Florida International University

FIU Digital Commons

FIU Electronic Theses and Dissertations

University Graduate School

$3-28-2003$

\title{
Sonority and its role in the acquisition of complex coda clusters by Spanish speakers learning English as a second language
}

Olena Drozd

Florida International University

DOI: $10.25148 /$ etd.FI15101229

Follow this and additional works at: https://digitalcommons.fiu.edu/etd

Part of the First and Second Language Acquisition Commons

\section{Recommended Citation}

Drozd, Olena, "Sonority and its role in the acquisition of complex coda clusters by Spanish speakers learning English as a second language" (2003). FIU Electronic Theses and Dissertations. 3087.

https://digitalcommons.fiu.edu/etd/3087 
Miami, Florida

SONORITY AND ITS ROLE IN THE ACQUISITION OF COMPLEX CODA CLUSTERS BY SPANISH SPEAKERS LEARNING ENGLISH AS A SECOND

LANGUAGE

A thesis submitted in partial fulfillment of the requirements for the degree of

MASTER OF ARTS

in

LINGUISTICS

by

Olena Drozd

2003 
To: Dean Arthur W. Herriott

College of Arts and Sciences

This thesis, written by Olena Drozd, and entitled Sonority and its Role in the Acquisition of Complex Coda Clusters by Spanish Speakers Learning English as a Second Language, having been approved in respect to style and intellectual content, is referred to you for judgment.

We have read this thesis and recommend that it be approved.

Feryal Yavas

Ellen Thompson

Mehmet Yavas, Major Professor

Date of Defense: March 28, 2003

The thesis of Olena Drozd is approved.

Dean Arthur W. Herriott College of Arts and Sciences

Dean Douglas Wartzok University Graduate School

Florida International University, 2003 


\section{ACKNOWLEDGMENTS}

I would like to express my sincere gratitude to my Major Professor, Dr. Mehmet Yavas, for his invaluable support and help with this thesis. Without his guidance, inspiration, kind attention, this study would not have become real.

My special thanks also go to the other two members of my thesis committee, Dr. Feryal Yavas and Dr. Ellen Thompson whose support and encouragement helped to fulfill this study.

All three of my committee members conceive a wonderful paragon of real scholars, good friends, excellent teachers. I am very thankful and honored to have been their student.

I also would like to thank all members of Truby family for their support of the Linguistics program at FIU. I was very pleased and honored to receive Truby Award in the year 2003 . 


\section{ABSTRACT OF THE THESIS \\ SONORITY AND ITS ROLE IN THE ACQUISTION OF COMPLEX CODA \\ CLUSTERS BY SPANISH SPEAKERS LEARNING ENGLISH AS A SECOND \\ LANGUAGE \\ by}

Olena Drozd

Florida International University, 2003

Miami, Florida

Professor Mehmet Yavas, Major Professor

This thesis looked at the concept of sonority and its influence in the acquisition of complex coda consonant clusters by ESL Spanish speakers. An experiment was performed to test the relationship between the sonority values of the segments of final complex clusters and the rate of errors. The goal of this thesis was to test the hypothesis that the Sonority Sequencing Principle was a powerful linguistic constraint that affected the acquisition of L2 phonology. The findings confirmed the idea that sonority played a crucial role in the phonological acquisition of L2 learners. Subjects reduced the least sonorant segment of the final cluster in order to achieve the minimal sonority descent. The choice of the segment could not be attributed to possible L 1 interference since Spanish did not license complex codas and any final obstruents except $/ \mathrm{s} /$. The minimal sonority distance factor effected the rate of errors. Subjects produced more errors in clusters where the sonority distance between their segments was small (e.g., one, two, and three). 


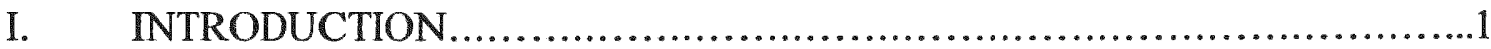

II. LITERATURE REVIEW .................................................. 6

General overview of sonority................................................6

Sonority and initial clusters.................................................... 16

Sonority and final clusters.................................................19

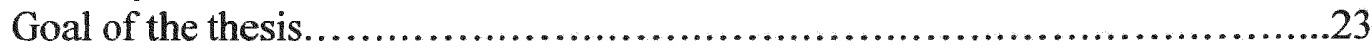

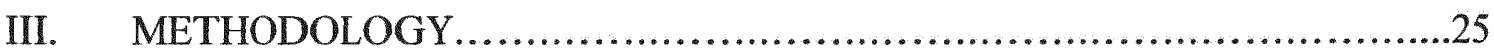

Hypotheses and research questions........................................25

Subjects and setting........................................................26

Spanish and English syllable structures...................................28

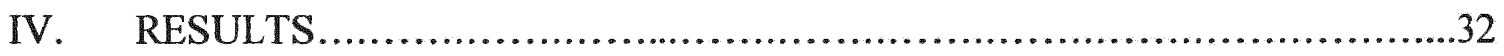

General findings..........................................................

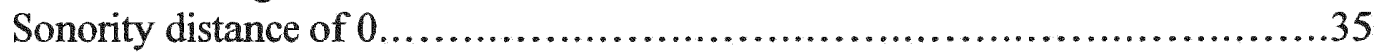

Sonority distance of 1 ..................................................... 37

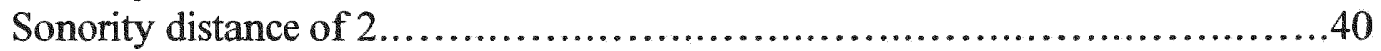

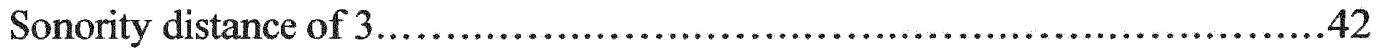

Sonority distance of 4 .....................................................43

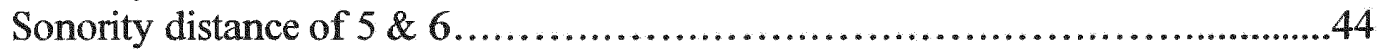

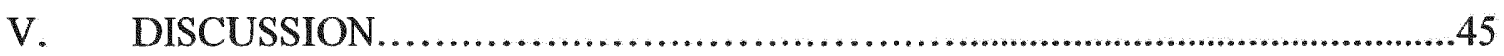

Types of errors..........................................................45

Place of articulation and its effect on errors...................................48

L1 transfer and its effect on the acquisition of ESL

codas by Spanish speakers..................................................50

Age of Learning. Early versus late Bilinguals.................................52

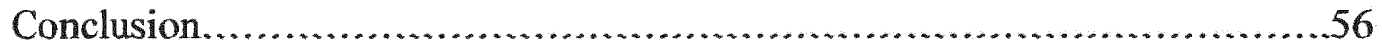

LIST OF REFERENCES ...........................................................59

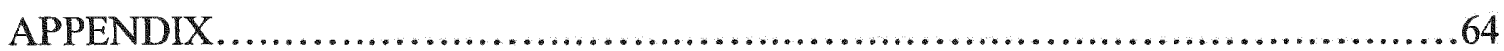




\section{LIST OF TABLES}

TABLE

PAGE

1. Examples of single consonant Spanish codas......................................28

2. Examples of word-internal complex Spanish codas................................29

3. Examples of phonemes that can occur in CC word-internal Spanish codas...........29

4. Mean $\%$ of reductions by each value of the sonority distance......................32

5. Mean $\%$ of correct productions by each value of the sonority distance..............32

6. Mean $\%$ of correct productions between early and late bilinguals...................33

7. Mean $\%$ of reductions made by each subject per each value of the sonority

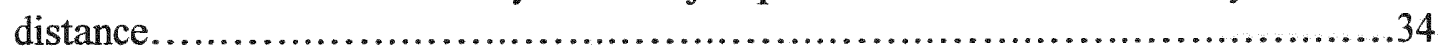

8. Mean $\%$ of correct productions made by each subject per each value of the sonority distance....................................................................... 34

9. Acquisition of consonants with respect to ease of articulation.......................38 
LIST OF SYMBOLS

SYMBOL

11

[ ]

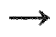

C

$\mathrm{CC}$

V

G

L

$\mathrm{N}$

$\mathrm{O}$

$\theta$

ə

$\int$

3

is

d3

y

i

I
DESCRIPTION

WORDS

Indicates Phoneme

Indicates Phonetic Representation

Becomes

Consonant

Consonant Cluster

Vowel

Glide

Liquid

Nasal

Obstruent

Voiceless Interdental Fricative

[0Ink]

Voiced Interdental Fricative

[briðd]

Voiceless Palato-Alveolar Fricative [ [IIp]

Voiced Palato-Alveolar Fricative

Voiceless Palatal Affricate

$\left[\mathrm{t} \int \varepsilon \mathrm{s}\right]$

Voiced Palatal Affricate

[d3Im]

Velar Nasal

[pInk]

High Front Tense Vowel

[lin]

High Front Lax Vowel

[sIp] 
$\varepsilon$

$æ$

v

ə

3

2

○

$\wedge$

$\alpha$

主
Lower-mid Front Unrounded Vowel [left]

Low Front Unrounded Vowel [græb]

High Back Rounded Vowel [kuk]

Mid Back Unrounded Lax Vowel [esolt]

Mid Back Unrounded Tense Vowel [13n]

Mid Back Unrounded Unstressed Vowel

[ænsə]

Lower Mid Back Rounded Vowel [bot]

Lower-Mid Back Unrounded Vowel [1 $\Lambda \mathrm{v}]$

Low Back Rounded Vowel

[dark]

High Back Unrounded Vowel [mìt'] 


\section{CHAPTER I}

\section{Introduction}

Adults learning a second or foreign language sometimes produce errors or nonnative substitutions, including ungrammatical utterances and foreign accent. These errors seem to be representative of an underlying system, yet different from their native language (NL) or target language (TL). The linguistic system of an adult language learner is called interlanguage (IL). This term was introduced by Selinker (1972) who defined it as "...the separate linguistic system based on observable output with results from a learner's attempted production of a target language norm" (p. 35). In recent years, there has been much research done on second language acquisition (SLA) related to the nature of the IL.

Since the early work of Lado (1957), second language learning has been seen as the development of a new set of habits. The role of a native language was considered to be significant. One of the most important components of the interlanguage, especially at the early stages was L1 transfer. The major theory of that time was associated with Contrastive Analysis Hypothesis $(\mathrm{CAH})$ which simply suggests that by comparing the $\mathrm{NL}$ and the TL it is possible to identify (predict) the aspects of the TL with which a learner will have difficulty. All learners' mistakes in pronunciation are believed to originate from negative transfer - when a learner tries to use inappropriate sounds of the NL in place of sounds in the TL. If both the NL and the TL have similar phonemes (e.g. /t/), then it is expected that the learner will not have any difficulty with these sounds in the TL. However, in many cases, learners do not produce errors predicted by the CAH. Hence, Wardhaugh ( 1970) introduced the strong and the weak versions of CAH. In the 
strong version, it is posited that one can predict errors, and in the weak version, the errors are explained after the fact. But even with the adoption of the above-mentioned versions, the CAH cannot predict which areas should be more problematic for a learner than others. Many researchers claim that the CAH cannot account for relative difficulty in producing the different sounds only by comparing the phonemes of respective languages. One needs to look at phonetic details in order to explain this fact.

Oller and Ziahosseiny's (1970) moderate version of the CA includes degrees of similarity between the NL and the TL. The authors' claim is that more similar features are acquired with greater difficulty than the dissimilar ones. They form their hypothesis on the idea that "whenever patterns are minimally distinct in form or meaning in one or more systems, confusion may result" (Oller and Ziahosseiny, 1970, p.186). One implication of this idea might be that languages that are more dissimilar would be easier to acquire than similar ones. No matter how enticing this claim might be, it presents a major flaw in that it applies mainly to individual phenomena, but not necessarily to whole languages. In second language acquisition, both negative and positive transfer occurs. In the acquisition of similar languages (e.g., Spanish and Portuguese), there will be more positive transfer than in dissimilar (e.g., Spanish and English). In this case, there will be more learning required for dissimilar languages.

During the past two decades, research has shown processes other than NL transfer are also at work in the IL phonology of the second language learner. Interest in IL universals originated with the work by Eckman (1977) who introduced the Markedness Differential Hypothesis (MDH). This theory states that unmarked phenomena are acquired before marked phenomena. The definition of "marked" is based on implicational 
hierarchies: $x$ is more marked than $y$ if the presence of $x$ implies the presence of $y$ but not vice versa. For example, possible syllable structures are related in a hierarchical relationship: if a language has the more marked CVC syllable types, it also has the unmarked CV syllable types.

Markedness predictions are found to be true when applied to voicing distinctions Yavas (1994) investigates the process of final devoicing in the IL. It is found that the speakers of languages that do not allow stops in final position (Japanese, Mandarin, Portuguese, etc.) tend to devoice final obstruents in their IL when learning a second language. Eckman's MDH predicts that final voiced obstruents are more marked and supports the claim that the process of final devoicing of obstruents is universal in nature.

The markedness corollaries also hold true when applied to final consonant cluster reduction. Eckman (1987) explores the process of final consonant cluster reduction in IL. Eckman argues that the process of cluster reduction (CR) reduces a more marked structure (e.g., tri-lateral cluster) to a less marked structure (e.g., bi-lateral cluster). The findings show that the IL phonology obeys universal constraints of markedness: tri-lateral consonant clusters are reduced to bi-lateral, as the former are more marked than the latter. Eckman and Iverson's (1993) investigations of coda consonants prove the validity of markedness relationships: the presence of more marked onset and coda clusters imply the presence of less marked ones.

A revised version of MDH is the Structural Conformity Hypothesis ( $\mathrm{SCH})$ introduced by Eckman (1991). Unlike the MDH which is related mainly to universals, the $\mathrm{SCH}$ also refers to $\mathrm{L} 1$ and $\mathrm{L} 2$. It claims that ILs obey primary language universals. So, for example, even speakers of those few languages that have a preference for closed 
syllables show a tendency in acquisition to produce open syllables (CV rather than $\mathrm{CVC}$ ) in the IL.

Tarone's (1976) study shows a tendency in L2 learners to modify syllable structure to a CV shape in the IL. She analyzes the speech of six ESL learners who are native speakers of Cantonese, Korean, and Portuguese. Subjects even tend to simplify consonant clusters which occur in their NL in order to obtain a CV pattern. Hence, she argues that the preference for a CV syllable operates as a process independent of transfer.

Linked to the $\mathrm{SCH}$, there is an issue of universal development factors. These are the processes that take place in the acquisition of the first language (L1) and also occur in SLA. Major (2001) introduces the Ontogeny phylogeny Model (OPM). This model looks at the interrelationships of three components of the IL: L1, L2 and U (Universal factors). The author proposes the following pattern of IL development: L2 increases, L1 decreases, and $U$ increases, then decreases. Major suggests that the same pattern can also be found in relation to style; as style becomes more formal, universal developmental factors increase while transfer decreases.

Eckman, Major, Tarone, and others working within this framework argue that learning of the second-language phonology is restricted by linguistic universal constraints on the structure of natural languages. The assumption is that universal constraints interact with $\mathrm{L} 1$ transfer and that the $\mathrm{IL}$ is the result of such interaction. These constraints help to account for the range of variability found in the learner's IL. L2 learners typically modify the syllable structures of the target language to fit their L1 structures. However, in many cases such substitutions do not seem to be L1-driven. Taking into consideration that the phonology of the IL is shaped not only by transfer, but also by universal factors, we 
would like to consider the role of sonority as one of the universal linguistic constraints affecting the phonology of the ESL learner. 


\section{CHAPTER II}

\section{Literature Review}

General Overview of Sonority

The examination of the syllable inventories of many languages of the world reveals that certain types of syllables are preferred over others. The study by Greenberg (1978) states that consonant-vowel syllable shape (CV) is present in the large majority of languages. Syllables with more complex structures (e.g. CCV, CVC, CVCC, CCVCC) are increasingly rare in the languages of the world. It has been noted also that when a language employs a complex syllable type such as $\mathrm{CCVCC}$, it is necessarily implied that $\mathrm{CV}$ and CVC syllables are also present in its inventory. Thus, no language contains the more elaborate syllable types without inclusion of the most basic syllable type (CV). This is known as an implicational universal; if a language allows a syllable type of a given complexity, it also allows the simpler syllable types. In children's early phonological developments we find consonant-vowel strings rather than just simple strings of consonants or strings of vowels. Moreover, the above fact has been also observed cross-linguistically. The CV syllable, thus, is legitimately called the core syllable, a universally preferred type of syllable.

The open or core syllable type (CV) plays a significant role in the $I L$ phonology as well. Adult learners assimilating complex syllable shapes modify them in order to get a more preferred syllable type: CVCC goes to CVC or CVC goes to CV. Benson (1988) provides evidence of the influence of language universals on the speakers' IL phonology, namely a universal preference for the open syllable. This preference shapes the phonology 
of the second language learner independently of native language transfer. Linguists have shown that the syllable has a hierarchical internal structure or organization. Selkirk (1982) claims that the syllable is typically divided into two primary units; the onset and the rhyme. The rhyme is subdivided into the nucleus (the peak of the syllable) and the coda. Selkirk supports the view of Pike (1967) claiming that there is a structure break between a syllable nucleus (peak) and its margins (onset and coda). This view is based on phonotactic considerations. If, in a CCV syllable, the first consonant is $/ \mathrm{p} /$ and the vowel is /a/, then the list of all possible sounds that can fill the position of the second consonant is controlled by $/ \mathrm{p} /$, not by $/ \mathrm{a} /$.

Treiman (1989) presents behavioral evidence in support of the distinction between onsets and rhymes. She argues that subjects treat them as separate units. Treiman teaches subjects a word game in which the onset of one word is blended with the rhyme of another. Then there is another game taught in which onsets and rhymes are divided. The findings show that those games are acquired more easily and with fewer errors where onsets and rhymes are kept intact. Another source of such evidence comes from errors in the spontaneous production of speech. Mackay (1972) examines errors made by German and English speakers where two words with similar meanings are blended (grasp and clutch equals grutch). Breaks seem to occur before the vowel rather than after it.

As has been mentioned earlier, from the core syllable that exists in almost all languages has sprung other types of syllables; therefore we may add to the core syllable a coda (CVC), or just delete the onset (V), or add the coda and delete the onset (VC). These three resulting syllable types, together with the core syllable, comprise the 
main syllable types. It has been perceived that complex onsets and codas are not constructed haphazardly.

Certain orderings within syllables are commonly found in many languages while other segment sequences either are not or are quite rare. The organization of segments within the syllable is governed by the Principles of Sonority Sequencing. It is worth mentioning here that sonority has never been defined to the satisfaction of most scholars. Below is the small list of sonority definitions that have been proposed in the literature. Ladefoged (1975) defines sonority as "...loudness of sound relative to that of other sounds with the same length, stress and pitch" (p. 221). Clements (1990) writes: "...the notion of relative sonority cannot be defined in terms of any single, uniform physical or perceptual property" (p. 298). As we see, there is no agreement between the scholars as to how to define the notion of sonority. Kenstowicz (1994) states that "... a simple phonetic correlate to the phonological property of sonority has yet to be discovered ...." (p. 254).

The idea that elements can be ranked in terms of sonority is first found in the work of Whitney (1865). But the first serious attempts to explain patterns of syllable structures are attributed to Sievers (1881) and later to Jespersen (1904). The Sonority Sequencing Principle (SSP) or Sonority Sequencing Generalization introduced by Sievers (1881) and later developed by Jespersen (1904) explains the tendency, within a syllable, of more sonorous segments to stand closer to the syllable peak than less sonorous ones. 
The SSP can be expressed in several basically equivalent ways. Parker (2002) offers the following statements as working definitions:

Sonority Sequencing Principle

(a) In every syllable there is exactly one peak of sonority, contained in the nucleus.

(b) Syllable margins exhibit a unidirectional sonority slope, rising toward the nucleus (p. 8).

Selkirk (1984) defines the SSP in the following way:

In any syllable, there is a segment constituting a sonority peak that is preceded and/or followed by a sequence of segments with progressively decreasing sonority values (p. 116).

Applying this principle to the languages of the world it is possible to account for such sequences as $/ \mathrm{mla} /, / \mathrm{mra} /$, and $/ \mathrm{alm} /$ where the most sonorous segments are closer to the peak (nucleus) of the syllable while other sequences such as $/ \mathrm{lma} /, / \mathrm{rla} /$, and $/ \mathrm{aml} /$ where less sonorous segments are closer to the peak are not frequent at all. As per the definition of sonority, vowels are the most sonorous elements (peaks) of the syllables, and consonants can be ranked, in order of greater to lesser sonority, as glides, liquids, nasals, fricatives, and stops.

However, one cannot disregard the fact that many languages do in fact allow some syllables that violate the Sonority Sequencing Principle. A few very typical examples from English would be words like school, scratch, stop, books, bags, etc. (/s/C and $\mathrm{C} / \mathrm{s} /$ sequences), where in $/ \mathrm{s} / \mathrm{C}$ clusters the more sonorous fricative is at the margin of the syllable before a less sonorous stop and in $\mathrm{C} / \mathrm{s} /$ clusters the less sonorous stop is before the more sonorous fricative. These "sonority reversals" are explained by positing some formal devices such as adjunction, as per Gierut (1999), extrasyllabicity, 
syllable affixes, degenerate syllables, complex phonemic units. Broselow (1993)

examines error patterns in the pronunciation of initial consonant clusters in English by native speakers of two dialects of Arabic: Iraqi Arabic and Egyptian Arabic. She finds that subjects insert a vowel into $/ \mathrm{s} / \mathrm{C}$ sequences such as sweater - [siwetar], slide - [silayd]. However, in words like study, ski they employ epenthesis, inserting a vowel before the initial cluster:[istadi] - "study"; [iski] - "ski". From these examples it follows that non-native speakers treat $/ \mathrm{s} / \mathrm{C}$ sequences differently depending on whether they violate the SSP or not. Thus, the corollary is that $/ \mathrm{s} /+$ stop clusters have a special marked status.

Support for a relative frequency of certain sequences can be found in the examples from child first language acquisition. It has been observed that strings like $/ \mathrm{ta} /, / \mathrm{da} /, / \mathrm{pa} /$, $/ \mathrm{ka} /, \mathrm{ba} /$, and $/ \mathrm{ga} /$ are mastered by children far earlier than $/ \mathrm{la} /$ or $/ \mathrm{ra} /$. The reason is that the former sequences provide a greater rise in sonority than the latter ones. In the case of $/ \mathrm{pa} /, / \mathrm{ta} /$, and $/ \mathrm{ka} /$ the sonority distance is $9 ;$ strings $/ \mathrm{ba} /, / \mathrm{da} /$, and $/ \mathrm{ga} / \mathrm{provide}$ the sonority distance of eight. Comparatively to this, syllable $/ \mathrm{ha} / \mathrm{has}$ a sonority distance of four, and for / $\mathrm{ra} /$ the distance is three.

Going back to hierarchical arrangements of sounds (sonority scales) one has to remember that there are quite a large number of competing scales of sonority hierarchy existing in the literature. The question is whether there has to be one universal scale for all languages or whether sonority scales are language-specific.

Zec (1995) conceives the following scale with minimal disctinctions: vowels > sonorants $>$ obstruents. He argues that even though his scale is not as sophisticated as the others, it 
distinguishes the ranking of segments with respect to sonority. Clements' (1990) universal sonority scale consists of only the four major natural classes of sounds (obstruents, nasals, liquids and glides) ranked in order from the least sonorous to the most sonorous.

$$
\mathrm{O}<\mathrm{N}<\mathrm{L}<\mathrm{G}
$$

Butt's (1992) sonority scale includes the voicing contrast of obstruents:

$$
\text { Voiceless } \mathrm{O}<\text { Voiced } \mathrm{O}<\mathrm{N}<\mathrm{L}<\mathrm{G}
$$

Looking at the structure of the Spanish syllable, Hammond (1999) offers the following sonority scale:

$$
\text { obstruents (1) < nasals (2) < liquids (3) < glides (4) < vowels (5). }
$$

Hankammer, and Aissen (1974) claim that an assimilation rule in Pali (a language of India) refers to a hierarchical relation among segments, namely sonority. The direction of the assimilation abides by the following rule: the consonant which is higher in sonority must assimilate to the one which is lower in sonority. When the consonants have the same sonority values, the first one assimilates to the second one. This process is very interesting in that it prefers low-sonority onsets over high-sonority codas (both favored by the SSP). The authors believe that the proper formulation of this assimilation rule requires a hierarchical arrangement among consonants, i.e. a scale of sonority.

Their scale is:

$$
\begin{aligned}
& \text { stops }<\text { s }<\text { nasals }<\text { l }<\text { v }<\text { y }<\text { r }<\text { vowels } \\
& \begin{array}{llllllll}
1 & 2 & 3 & 4 & 5 & 6 & 7 & 8
\end{array} \\
& \rightarrow \text { greater sonority } \rightarrow
\end{aligned}
$$


They argue that it would have been impossible to account for certain assimilations in Pali only on the basis of Chomsky and Halle's (1968) binary distinctive feature theory. Selkirk (1984) proposes a sonority scale for non-syllabic segments:

$$
\mathrm{p}, \mathrm{t}, \mathrm{k}<\mathrm{b}, \mathrm{d}, \mathrm{g}<\mathrm{f}, \theta<\mathrm{v}, \mathrm{z}, \mathrm{\gamma}<\mathrm{m}, \mathrm{n},<\mathrm{l}<\mathrm{r}
$$

The 10-point sonority scale of Hogg and Mc Cully (1987) is one of the most detailed sonority scales:

Voiceless stops (1) < Voiced stops (2) < Voiceless fricatives (3) < Voiced fricatives (4) $<$ Nasals $(5)<$ Laterals $(6)<$ Flaps $(7)<$ High vowels $(8)<$ Mid vowels $(9)<$ Low vowels $(10)$. As we can see, they make distinctions between obstruents, vowel heights, and laterals and $r$-sounds. By distinguishing voiceless sounds from voiced, stops from fricatives, and laterals from r-sounds, a refined sonority scale such as this makes it possible to provide solid evidence for why certain sequences of sounds are preferred over others (e.g., /pa/ vs /ba/;/la/ vs /ra/).

While the SSP accounts for the universally unmarked syllable structures, it does not complete the picture. Most languages allow onset clusters such as /pla/, /pra/ while syllables as $/ \mathrm{psa} /, \mathrm{pfa} /, / \mathrm{pna} /$ are much less frequent. All these sequences obey SSP, but the difference between them is in the minimal sonority distance separating two consonants in each onset. Thus, the majority of languages invoke a constraint concerning minimum sonority distance among tautosyllabic consonant clusters (sequences of consonants in the same syllable) as a supplement to the SSP. For example, the difference in sonority between a voiceless stop and the liquid in Spanish is high, as in forms /playa/ 'beach' (i.e. from 1 to 3). On the other hand, syllables beginning with a stop followed by' 
the nasal, like /pna/, or /tma/ do not occur in Spanish since the difference between a stop and a nasal is only one step apart on a sonority scale (i.e./p/ -1 to $/ \mathrm{n} /-2$ ). The minimal sonority distance in these examples is calculated according to the sonority scale proposed by (Hammond 1999).

Another sonority-based constraint that is found in many languages is called the Syllable Contact Law by Murray and Vennemann (1983). It is stated by this principle that the preferred contact between two adjacent syllables is when the segment ending the first syllable is higher in sonority than the segment beginning the second syllable (e.g., in the word /fo.rest/ the vowel /o/ that ends the first syllable has a higher sonority value than the consonant $/ r$ / that begins the second syllable).

Clements (1990) offers a pivotal mechanism based on sonority relationships that is known as Sonority Dispersion Principle. The essence of this is to maximize the onset-to-nucleus sonority slope and minimize the nucleus-to-coda sonority slope. Clements argues that the syllable consists of two parts or demisyllables; the first includes the onset plus nucleus, and the second includes the nucleus plus coda. This principle correctly predicts that the universally preferred syllable type, $\mathrm{CV}$, has to have an onset consonant with the lowest sonority index (e.g., /ta/ is the most preferred onset as / $t /$ has the lowest sonority value). In codas, it needs to be reversed in accordance with the SDP (Sonority Dispersion Principle).

Another area of phonology in which sonority plays a role is a stress assignment. The heavier the syllable is, the more likely it is to attract stress. Sonority is claimed to be one of the most significant factors determining segmental weight, especially among 
vowels. Based on different case studies in such works as Bianco (1996), Kenstowicz (1996), and de Lacy $(1997,2002)$, we can posit the following hierarchy of vowel weight/sonority:

$$
a>e, o>i, u>\theta>\dot{1}
$$

As we can see from the scale above, two different dimensions correlate with sonority distinctions; height and peripherality. Vowels that are higher in sonority tend to be longer in phonetic duration than those lower in sonority.

Going back to the internal structure of the syllable, namely onset and coda, one has to mention that sometimes onsets and codas may involve a complex structure as in the occurrence of consonant clusters. Greenberg (1978) tries to formulate a number of universals with respect to initial and final consonant clusters that are based on samples from 104 languages. These generalizations are mainly focused on the marked status of clusters, preferred types of assimilation, preferences based on relation to the peak of the syllable. Besides generalizations regarding consonant clusters, the author pinpoints the value of a good definition of the concept "consonant cluster". He believes that the best definition of a cluster was presented by Trubezkoy (1958) as “... produced by a single articulatory movement or by means of a progressive dissociation of an articulatory complex" (p. 58). He further argues that initial and final consonant clusters function independently and, hence, have to be treated separately. He notes that consonants in initial clusters tend to occur in obstruent $(\mathrm{O})$, nasal $(\mathrm{N})$, liquid $(\mathrm{L})$, glide $(\mathrm{G})$ order, while consonants in final clusters tend to occur in the reverse order. These findings are in compliance with the SSP. As to the markedness status of clusters, he notes that shorter 
clusters are preferred to longer ones, i.e. “... if syllables containing sequences of $n$ consonants in a language are to be found as syllabic types, then sequences of $n-1$ consonants are also to be found" (Greenberg, 1978, p. 249). As a corollary, shorter clusters are preferred over the longer ones. When talking about the preferred types of assimilation, homorganic nasals-obstruents combinations are more common than heterorganic. In terms of their position in the syllable, such combinations are favored where the more sonorous elements are closer to the peak than obstruents. The voiced consonants are preferred when they are closer to the nucleus of the syllable.

All these generalizations lead us to the issue of markedness and its relationship to sonority in reference to consonant cluster sequences. The question of markedness in interlanguage (IL) phonology is raised by Carlisle (1994). The main conclusion is that less marked structures are acquired easier and earlier and, in relation to a variability concept, they are less often modified. Speaking about the markedness status of onsets and codas of English, he refers to one of the generalizations made by Greenberg (1978) concerning initial consonant clusters: “...the existence of one nasal + liquid cluster implies the existence of at least one obstruent-liquid cluster" (p. 264). Strictly speaking, the obstruent-nasal consonant clusters are less marked. He pinpoints the fact that longer onsets and codas are more marked than shorter ones. Even when compared to each other, onsets and codas show distinctions as to the markedness status: codas are more marked than onsets, and they are modified more frequently. As we mentioned earlier, this is explained by the universal tendency for the CV syllable type. Baptista and da Silva Fiho (1997) explore markedness in terms of sonority and how sonority can affect the 
production of English single-consonant codas by native speakers of Brazilian Portuguese. Their findings support the claim that marked structures are modified more frequently than unmarked ones. The authors find that codas with obstruents are modified more frequently with epenthesis and create more difficulties for learners than codas with nasals

The role of sonority constraints in the acquisition of English consonant clusters (initial and final) has been the subject of research both in normal child and disordered phonology as well as in L2 learning. Recent studies on the modifications of onset clusters reveal the fact that sonority plays a crucial part in child speech.

\section{Sonority and initial clusters}

Chin (1996) investigates the realizations of initial clusters in delayed phonological systems. He provides evidence that these realizations are in compliance with the Sonority Sequencing Principle (a stop-liquid consonant cluster is realized as a stop; a fricative-liquid consonant cluster is realized as a fricative; fricative-stop consonant cluster is realized as a stop). In all these cases, the most sonorous segment of the consonant cluster is omitted in order to provide the sharpest rise in sonority from the consonant to the peak of the syllable.

Another study that looks at the role of the SSP in the acquisition of onset clusters and adjuncts by children with phonological disorders is performed by Gierut (1999). The results of the experiment support the idea that the occurrence and use of marked initial clusters imply the occurrence and the use of the unmarked ones. In this case, the term "marked" refers to the cluster with the lowest sonority distance between segments. 
Ohala (1999) researches on the phonological process of consonant cluster reduction in children with normal language development. For initial clusters, she predicts a reduction that creates the sharpest rise in sonority from the margin of the syllable to the peak. The study was performed with sixteen English-speaking children in sets of two experiments. The results support the prediction that children's reductions are sonority-driven (e.g., [stig] is reduced to [tig]) in that children retained the least sonorous segment in initial clusters.

Stimuli containing impossible clusters of English are conceived in Experiment 2. Some of the clusters are phonologically similar to clusters that do occur in English. The findings show that in the reduction of initial clusters, children preserve the least sonorous segment (e.g., in the fricative-glide consonant cluster, a fricative is kept; in the stop-glide consonant cluster, a stop is kept). However, the modifications children make in relation to non-native English clusters that are phonologically dissimilar to English clusters do not obey the SSP.

The role of sonority sequencing in initial clusters is also investigated with respect to the IL phonology. Broselow and Finer (1991) investigated the mastery of the English initial clusters by 24 native speakers of Korean and Japanese. Their hypothesis was that clusters with a smaller sonority distance between the first and the second member (e.g., /fr/ from 3 to 7 ) are more problematic than clusters with a larger difference in sonority between the segments (e.g., /pj/ from 1 to 8 ). The results show that there are a greater number of errors for consonant clusters with low minimal sonority distance (e.g., /fr//ff/) as compared to those with large sonority distance values (e.g., /py/,/pr/). 
This fact cannot be attributed to transfer from their native language since neither Korean nor Japanese license /pr/ and / br/ clusters yet these clusters were not a problem. The differences in the treatment of these clusters are in compliance with the predictions made by sonority sequencing. It follows that subjects' productions follow universal markedness constraints; in that more marked clusters are acquired later than unmarked ones.

Aphasic patients provide us with behavioral data on the effect sonority employs in speech errors. The study by Romani and Calabrese (1998) provides solid evidence that the SSP also applies in explaining errors by aphasics. It has to be noted that this is the first study reporting systematic effects of sonority-based complexity in aphasia. The phonological errors produced by the subject, DB (an articulatory disfluent patient), show the tendency to produce syllable configurations which are less complex (marked) than the target in terms of sonority sequencing. In onsets, DB deletes the segment of higher sonority and produces the least marked syllable (e.g., an obstruent-liquid consonant cluster is reduced to an obstruent; an obstruent-glide consonant cluster is reduced to an obstruent).

The work of Caplan and Nespoulous (1990) supports the claim that consonantal omissions in onset constituents (by far the most frequent type of error produced by aphasic subjects) fall under rules predicted by the sonority hierarchy. In all cases, the aphasic subject deletes the liquid in a sequence of obstruent-liquid as well as in a sequence of obstruent-liquid-glide. The omission of the more sonorous segment increases the difference in sonority between the nucleus and the onset resulting in a syllable closer to the universally preferred syllable type (CV). 
As the focus of my study and interest lies primarily in the acquisition of the final clustersof English, I would like to present a summary of the research done in this area. The data show that sonority constraints are not limited to onset clusters only. The study of Ohala (1999), mentioned earlier, deals with the process of final consonant cluster reduction in sixteen normally developing English-speaking children without phonological delays. She claims, that this process also applies to $I L$ phonology, is systematic and regular. The reduction seems to be based on the SSP rather than on a certain order of segments within the cluster or a certain manner of articulation. For codas, sonority hierarchy predicts a reduction that creates a minimal descent in sonority from the peak of the syllable to the consonant.

$$
\begin{aligned}
& \text { e.g. liquid-stop } / \mathrm{lp} / \quad \text { liquid } / \mathrm{I} / \\
& \text { liquid-fricative } \quad \text { lf/ liquid // }
\end{aligned}
$$

Sonority hierarchy also predicts an interaction between cluster position (syllable-initial or syllable-final) and the type of the reduced consonant (e.g., if syllable-final, a fricative-stop cluster is reduced to a fricative).

There are two types of stimuli in Experiment 1: picture stimuli (28 colored pictures of imaginary animals) and word stimuli (monosyllabic nonsense words). The items are designed in such way that no reduction could produce a real word.

The results of Experiment 1 fully support the Sonority Hypothesis. Children reducing a final consonant cluster retained the most sonorous segment (e.g., [d^st] $-[\mathrm{d} \wedge \mathrm{s}])$. Experiment 2, exploring the reduction in non-native English 
clusters, provides evidence that a minimal descent in sonority is a natural tendency (e.g., in reduction of final stop-fricative cluster, children retain more fricatives: $52 \%$ than stops: 16\%). Overall, the study of Ohala (1999) justifies the claim that cluster reduction is based on the Sonority Hypothesis. As per the SSP, the consonant omitted from the cluster is the one that least conforms to the shape of the core syllable (CV). The acquisition of consonant clusters by four monolingual German children and by four monolingual Spanish children is the subject of the study by Lleo and Prinz (1996). In the early stages of acquisition, target clusters are reduced to a single consonant. The assumption is that the selection of the segment is not arbitrary but depends on such universals as feature markedness and sonority. The data were collected by means of a longitudinal study. The findings show that simplifications of final consonant clusters are subject to the SSP. In coda target clusters composed of a sonorant plus an obstruent (e.g.,/ns/, the sonorant (nasal) was selected in forty-three out of forty-seven cases, as compared to the obstruent (fricative) being selected only four times. In coda target clusters composed of a fricative plus a stop (e.g.,/st/), the fricative was selected in twenty-four out of twenty-five cases, whereas the stop was selected only once.

The study by Dravina (1990) deals with the cluster acquisition process in three Latvian monolingual children. In spite of the fact that Latvian is rich in consonant clusters, children have problems with the mastery of such sequences. The results represent the fact that modifications of final consonant clusters are sonority-driven. Subject 1 changed the second consonant of the consonant cluster to another obstruent consonant $(/ \mathrm{ns} / \rightarrow / \mathrm{nt} / ; / \mathrm{ms} / \rightarrow / \mathrm{mt} / ; / \mathrm{ss} / \rightarrow / \mathrm{lt} /)$, providing greater sonority distance 
between the two members of the consonant cluster. Subject 2 reduced consonant cluster $/ s t /$ to $/ s /$ and, hence, retained the more sonorant consonant which is in full compliance with the SSP.

The effect of sonority on the acquisition of final English codas has also been illustrated in the interlanguage phonology. Tropf (1987) investigates the role sonority plays in L2 phonological acquisition of German consonant clusters by 11 adult native Spanish speakers. Clusters that are in compliance with the SSP are modified less frequently than those that are not in compliance with this principle. For example, a two-segment cluster such as stop plus a fricative (/ts/), which violates the SSP because the less sonorant element (stop) is placed before a more sonorant segment, (fricative) is modified more frequently. When clusters are modified by a deletion one of the members, the results show the following tendency: obstruents are more frequently omitted than sonorants. Moreover, there is a particular pattern within the natural classes of sounds themselves. Within the obstruents, stops are omitted more frequently than fricatives, and within the sonorants, nasals are omitted more often than laterals. Another finding is that the more sonorant the final target consonant is, the more likely it will be realized in the IL and not omitted. Thus, the assumption is that sonority is a factor operating independently of native language (NL) and target language (TL).

Hansen (2001) investigates the acquisition of English syllable codas by native speakers of Mandarin Chinese. She particularly looks at linguistic constraints, including sonority that influence the acquisition of codas. It has to be noted that Mandarin Chinese has a relatively simple coda structure as compared with English. In spite of the fact that 
results show that sonority plays a minimal role in the acquisition of single and two-member codas, it is a crucial factor in the mastery of three-member codas. The learners have greater difficulty with such clusters as liquid-stop-fricative (/lps/) or nasal-stop-fricative (/nts/). All these sequences violate the SSP; all of them have a minimal descent in sonority from the first to the second member of the consonant cluster, but they have a rise in sonority from the second to the third member of the consonant cluster. Thus, learners modify such sequences more often and have greater difficulty with them compared to those codas where there is a gradual fall in sonority as predicted by the SSP.

The research that has been examined here shows the universal nature of the principles of sonority posited by phonological theory. Various examples from child phonology, subjects with phonological disorders, and $I L$ phonologies have revealed strong sensitivity to sonority indexing of sounds by different populations of developing phonologies. 
As we have seen, sonority seems to play a pivotal role in all aspects of phonological developments, in cases of normal and disordered child phonologies, errors by aphasic patients, and IL phonologies. These last two groups require more attention. Individuals with phonological disorders require more treatment or remediation while ESL speakers are in great need of appropriate instruction tools to assist them in mastering a second language in a time-saving fashion. In spite of all the research that has been done, it is obvious that more studies are needed to explore phonological acquisition of ESL and its interrelationship to the Sonority Theory.

The primary goal of this thesis is to look at the effect that sonority plays in second language learning. I will study error patterns demonstrated by adult ESL Spanish speakers when attempting complex coda clusters of English and how these patterns correlate with the Sonority Sequencing Principle. My hypothesis is that subjects will reduce coda clusters to whichever segment results in the least complex, i.e. unmarked syllable as restricted by sonority. I also predict that reduction errors can be highly attributed to the sonority distances between segments of coda clusters; subjects will produce more reductions when attempting clusters consisting of segments with smaller sonority distances between. I also hypothesize that there is an implicational relationship regarding the incorrect/correct productions. In other words, an error with a cluster that has sonority distance " 5 " (e.g., [belt] $\rightarrow$ [bel]) implies errors with codas having a sonority distance of " 4 " (e.g., [bent] $\rightarrow$ [ben] $),$ "3" (e.g., [hænd] $\rightarrow$ [hæn] $)$, and "2" (e.g., $[$ IIsp $] \rightarrow[$ IIs $]$ ), but not vice versa. These findings can help us to understand and 
articulate a theory of sonority and its applications in the acquisition of final coda clusters of English.

The thesis also addresses the issue of which linguistic constraints interact in the acquisition of L2 phonology. I would like to support the claim that L1 transfer cannot be considered a paramount factor in shaping the phonology of ESL speakers. The effect of transfer cannot explain why certain clusters are more difficult than others for ESL Spanish speakers since Spanish does not license any complex coda sequences. On the other hand, I will claim that certain universal linguistic constraints such as final obstruent devoicing, along with sonority sequencing, will play a significant role in the acquisition of complex codas. After analyzing the data, I will point out the implications of these findings with respect to second language learning. 


\section{CHAPTER III}

\section{Method}

\section{Hypotheses and research questions}

As it was mentioned in the previous chapter, target consonant clusters have been the subject of investigation in children's early phonological developments, IL, and disordered phonologies. The research shows that the way subjects modify final consonant clusters can be related and linked to a universal phonological constraint, namely sonority. This constraint or factor induces such realizations that cannot be explained either by the phonological patterns of the native language or those of the target language. In a complex coda cluster (e.g., /st/), subjects delete the least sonorant segment (stop) more frequently than the one that has a larger sonority value (fricative). Such simplification of the consonant cluster seems not to be dependent upon the presence or absence of such a sequence either in the native language or in the target language.

The subject of investigation of the present study is the acquisition of two-member English coda clusters by ESL Spanish speakers. Spanish offers a wonderful opportunity to test whether sonority influences L2 phonological acquisition. Speakers of Spanish are chosen because the language does not allow complex coda clusters. English codas are very difficult for these learners to acquire.

The following research questions are addressed in this study:

1. What error patterns can we observe when coda clusters are produced by non-native speakers of English?

2. To what extent can $\mathrm{L} 1$ transfer effect the realization of coda clusters by Spanish ESL speakers? 
3. Does the place of articulation of the consonant cluster segments (CC) affect the errors?

4. Will there be any difference in the production between the early and late bilingual subjects?

There are two hypotheses posited:

Hypothesis \# 1: $\quad$ Subjects will produce errors in compliance with the SSP to obtain a minimal sonority descent in codas (e.g., /sp/ $\rightarrow / \mathrm{s} /$ ).

Hypothesis \# 2: $\quad$ There will be an implicational relationship regarding the incorrect/correct productions. The error in a cluster with the sonority distance (SD) of 4 will imply errors in codas with the SD of 3,2 , and 1 , but not vice versa.

\section{Subjects and setting}

Fifteen adult speakers of Spanish (both males and females) are chosen as participants in this study. Approximately half of them (7) are considered to be early bilinguals: age of learning (AOL) ranges from 3 months to 10 years, and the rest (8) are late bilinguals: AOL is from 20 years to 40 years. All subjects work in different positions in a shipping company. One set of data is collected from each of the participants. The data are taken from a thirty minute tape-recording of each subject in a quiet conference room of the office where the participants work. The subjects are given ninety Spanish words written on flash-cards. The idea to present words written in Spanish rather than in English is intended to elicit the most naturalistic production possible. If the words were given in English, subjects most likely would tend to read them in English which is not what we are looking for in this study. The participants are required to pronounce these words 
aloud in Spanish and then in English. These words are chosen systematically to represent complex coda clusters with different values of SD $(1$ - pearl, 2 - fast, 3 - sand, 4 - tent, 5 - bird, 6 - park). Broselow \& Finer (1991) introduced the minimal sonority distance (MSD) parameter as a crucial factor in the acquisition of L2 syllables. The MSD parameter measures variation among consonant clusters based on the SD between the adjacent elements. They claim that the lower MSD there is between the segments of the consonant cluster, the more difficult this cluster is to acquire due to the constraints on sonority sequencing in the grammar. What follows is that grammars prefer a larger, rather than smaller difference in the SD between the two segments in a complex onset/coda syllable. Hence, it can be predicted that Spanish speakers will have greater difficulty with clusters having smaller sonority distances between segments (e.g., $1-/ \mathrm{rl} /, 2-/ \mathrm{sk} /, 3-/ \mathrm{nd} /$, and $4-/ \mathrm{lz}$ ) compared to those sequences that have larger sonority distances between the members (e.g., 5 - /lt/, and 6-/rk/). Since Spanish does not allow for complexity in final codas, it has a coda setting of five because the largest allowable difference between consonant-type values is four (i.e. glides have sonority value of five, and stops - one). This predicts that there will be no or small transfer effects in complex L2 codas. After making each tape-recording, the investigator carefully transcribed each word phonetically using the International Phonetic Alphabet (IPA). Each word was transcribed twice in order to ensure the reliability of each transcription. Each tape was heard twice and transcribed. Doubtful cases, which were not more than $1 \%$ of the data, were eliminated. 
Before reviewing the data, it is important to first examine the difference between English and Spanish syllable structures, particularly codas. Spanish syllable codas consist of either an empty constituent or one consonant. Spanish does not allow complex CC codas. Furthermore, it is worth noting that single C Spanish codas are very restricted:

Consonants

$\mathrm{C}$

$\mathrm{CC}$
Codas

$/ \mathrm{n} /, / \mathrm{l} /, / \mathrm{r} /, / \mathrm{s} /, / \mathrm{d} /$

$* * * * * * * * * * * * * *$

Table 1 Examples of single Spanish codas

\begin{tabular}{llll}
\hline Number & Word & Consonant & Phonetic transcription \\
\hline 1. & pan & $/ \mathrm{n} /$ & [pán] \\
2. & papel & $/ /$ & [pa.pél] \\
3. & comer & $/ \mathrm{r} /$ & [ko.mér] \\
4. & tos & $/ \mathrm{s} /$ & [tós] \\
5. & pared & $/ \mathrm{d} /$ & [pa.réđ] \\
\hline
\end{tabular}

Word-final single C codas in Spanish are extremely weak and unstable. As a result of such instability, these word-final codas undergo numerous phonological modifications. They are frequently deleted in informal speech. For example, the deletion of the phoneme /d/ is almost universal in informal speech, and the deletion of $/ \mathrm{s} /$ is also very frequent.

A review of complex CC syllable-final (word-internal) codas reveals that they consist of two heterogeneous consonants. Interestingly, the slot of the second segment is almost always occupied by the obstruent $/ \mathrm{s} /$. This coda final /s/ appears after glides, liquids, nasals, and obstruents (seeTable 2 below.). 


\begin{tabular}{lll}
\hline Coda clusters & Examples & Transcription \\
\hline$/ \mathrm{ys} /$ & aislar & [ays.lár] \\
$/ \mathrm{ws} /$ & claustro & [kláws.tro] \\
$/ \mathrm{rs} /$ & perspicaz & [pers.pi.kás] \\
$/ \mathrm{ns} /$ & monstruo & [móns.trwo] \\
$/ \mathrm{bs} /$ & abstracto & [aßs.trak.to] \\
$/ \mathrm{ks} /$ & extensor & [eks.ténso] \\
$/ \mathrm{yn} /$ & veinte & [beyn.te] \\
$/ \mathrm{wk} /$ & auxilio & [awk.sí.lyo] \\
$/ \mathrm{wn} /$ & aunque & [áwn.ke] \\
\hline
\end{tabular}

The two other consonants that are licensed to appear in the second segment slot are the nasal $/ \mathrm{n} /$ and the obstruent $/ \mathrm{k} /$. But due to the fact that they are extremely rare in Spanish, we can claim that word-internal Spanish codas may consist of six possible phonemes followed only by the phoneme $/ \mathrm{s} /$.

Table 3 Examples of phonemes that can occur in CC word-internal Spanish codas

\begin{tabular}{ll}
\hline Consonant 1 & Consonant 2 \\
\hline$/ \mathrm{y} /$ & $/ \mathrm{s} /$ \\
$/ \mathrm{w} /$ & $/ \mathrm{s} /$ \\
$/ \mathrm{r} /$ & $/ \mathrm{s} /$ \\
$/ \mathrm{n} /$ & $/ \mathrm{s} /$ \\
$/ \mathrm{b} /$ & $/ \mathrm{s} /$ \\
$\mathrm{k} /$ & $/ \mathrm{s} /$ \\
\hline
\end{tabular}

Among these codas, only the glide $+/ \mathrm{s} /$ codas are frequent in Spanish.

To sum up, it is posited that the Spanish syllable has an obligatory constituent (always a vowel) that represents its nucleus and up to three optional consonants in its onset and a maximum of two consonants in its coda. The onsets and codas of Spanish are occupied by the least sonorant constituents. Whereas Spanish does not possess complex CC codas in its inventory word-finally, English has a large variety of complex codas at the end of the word: 

$\mathrm{C}$ :
pot
[pot]
$\mathrm{CC}: \quad$ lisp
[1Isp]
CCC: $\quad$ curves
[k3rvz]
CCCC: texts [teksts]

Codas may contain any single consonant (e.g., /t/ - cat, /g/ - dog, /m/ - scum, /z/ - lease, $/ \mathrm{n} /$ - vine, etc.). If there are two consonants in a coda, the second must be an obstruent. Indeed, the majority of $\mathrm{CC}$ codas are formed by a nasal + obstruent or a liquid + obstruent. Then there is a smaller class ending in two obstruents. There is a very interesting collocational restriction imposed on such codas: the second consonant of the coda must be a coronal sound. There are, however, counterexamples to such a claim (e.g., ask, lisp, etc.). As per Selkirk (1982) “.../s/ plus obstruent groups can qualify as a single consonant" (p. 330). So, in the cases mentioned above, sequences /sp/ and /sk/ are considered to be the single coronal consonant $/ \mathrm{s} /$. The fricative $/ \mathrm{s} /$ is the only fricative permitted in the English codas before non-coronals, as attested to by the impossibility of such forms as *lefp or *lefk in contrast to 'left', which ends in a coronal (Roca \& Johnson, 1999). What is obvious is that we find a sequence of sonorant plus obstruent in CC codas, and in English it is impossible to reverse this order.

$\begin{array}{ll}\text { lamp } & \text { *lapm } \\ \text { help } & \text { *help }\end{array}$

We can find another collocational restriction affecting the codas in Selkirk (1982): if there is a second consonant in the coda, the first may not be $/ \mathrm{b} /, / \mathrm{g} /, / \mathrm{v} /, \mathrm{tg} /$, $/ \mathrm{d} 3 /, / \mathrm{S} /$, or $/ 3 /$. English has also three-member clusters as in the words like [prompt], 


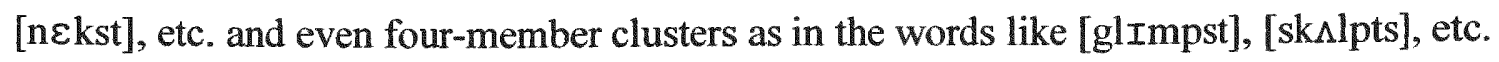
All these clusters have a coronal obstruent: $/ \mathrm{s} /$ and $/ \mathrm{t} /$. As we can see from the everything mentioned above, there is a great difference between Spanish and English syllable structures. In conclusion, it is obvious that English possesses a diverse variety of word-final consonant clusters whereas Spanish not only prohibits these, but also imposes severe restrictions on single-consonant coda clusters. 


\section{CHAPTER IV}

Results

General findings

Generally, the results confirm the idea that when a sonority distance (SD)

between two segments of the consonant cluster is small, the number of errors increases.

For example, the cluster / $\mathrm{rt} /$ has a larger $\mathrm{SD}$ (from 7 to 1 ) and is more natural than the sequence /nz/, which has a smaller SD (from 5 to 4 ). Therefore, the prediction was that subjects would have reduced such clusters of a smaller SD more frequently.

Table 4 Mean \% of reductions by each value of sonority distance

\begin{tabular}{ll}
\hline Sonority distance value & Percentage \\
\hline SD 1 & $46.40 \%$ \\
SD 2 & $32.05 \%$ \\
SD 3 & $24.47 \%$ \\
SD 4 & $10.08 \%$ \\
SD 5 & $.0000 \%$ \\
SD 6 & $.0000 \%$ \\
\hline
\end{tabular}

Thus, we can assume that there is a universal relationship between production difficulty and the SD. On the other hand, subjects had greater success with coda clusters with greater sonority difference between members.

Table 5 Mean \% of correct productions by each value of sonority distance

\begin{tabular}{ll}
\hline Sonority distance value & Percentage \\
\hline SD 1 & $21.10 \%$ \\
SD 2 & $31.07 \%$ \\
SD 3 & $39.98 \%$ \\
SD 4 & $62.48 \%$ \\
SD 5 & $88.48 \%$ \\
SD 6 & $100.00 \%$ \\
\hline
\end{tabular}

The Repeated Measures Anova test was performed to test the significance of differences in reductions and correct productions by each value of sonority distance. The differences 
were found to be significant, $p<0.5$. Another pattern emerged that related to the modifications of clusters in erroneous productions. When subjects reduced clusters $(\mathrm{CVCC} \rightarrow \mathrm{CVC})$, the resulting coda conformed with the minimal sonority descent. For example, subjects modified clusters with greater $\mathrm{SD}$ in such a way as to eliminate the segment with lower sonority value, and hence provided a minimal sonority descent.

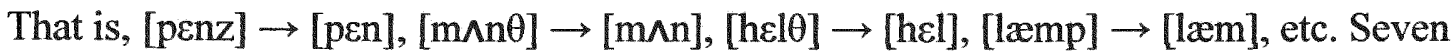
out of fifteen participants in the experiment are considered to be early/simultaneous bilinguals. Their age of arrival (AOL) ranges from 3 months to 10 years. The T-Test for differences in correct productions between early and late bilinguals was performed after the data collection. The differences were found to be statistically insignificant, but the data in Table 6 show that, overall, early bilingual subjects had more correct productions that late bilingual participants.

Table 6 Mean \% of correct productions between early and late bilinguals

\begin{tabular}{|c|c|c|}
\hline Sonority distance value & $\begin{array}{l}\text { Early } \\
\text { Late }\end{array}$ & Percentage \\
\hline \multirow[t]{2}{*}{ SD 1} & Early & $30.50 \%$ \\
\hline & Late & $14.28 \%$ \\
\hline \multirow[t]{2}{*}{ SD 2} & Early & $35.29 \%$ \\
\hline & Late & $27.95 \%$ \\
\hline \multirow[t]{2}{*}{ SD 3} & Early & $53.33 \%$ \\
\hline & Late & $29.54 \%$ \\
\hline \multirow[t]{2}{*}{ SD 4} & Early & $68.05 \% \%$ \\
\hline & Late & $63.95 \%$ \\
\hline \multirow[t]{2}{*}{ SD 5} & Early & $93.61 \%$ \\
\hline & Late & $82.45 \%$ \\
\hline \multirow[t]{2}{*}{$\mathrm{SD} 6$} & Early & $100.00 \%$ \\
\hline & Late & $100.00 \%$ \\
\hline
\end{tabular}

The hypothesis regarding the implicational relationship in incorrect/correct productions, based on individual subjects' performance, was partially confirmed in 7 out of 15 cases. 
The rest of the subjects showed deviation in the number of incorrect/correct productions in clusters with an SD of 2 and 3.

Table 7 Mean \% of reductions made by each subject per each value of sonority distance

\begin{tabular}{lllllll}
\hline Subject ID & SD1 & SD2 & SD3 & SD4 & SD5 & SD6 \\
\hline JC & $44.44 \%$ & $27.27 \%$ & $20 \%$ & $0 \%$ & $0 \%$ & $0 \%$ \\
LW & $57.14 \%$ & $36.36 \%$ & $33.33 \%$ & $0 \%$ & $0 \%$ & $0 \%$ \\
LC & $50 \%$ & $33.33 \%$ & $18.18 \%$ & $0 \%$ & $0 \%$ & $0 \%$ \\
RB & $50 \%$ & $50 \%$ & $20 \%$ & $0 \%$ & $0 \%$ & $0 \%$ \\
CF & $50 \%$ & $36.36 \%$ & $27.27 \%$ & $18.18 \%$ & $0 \%$ & $0 \%$ \\
IF & $50 \%$ & $50 \%$ & $18.18 \%$ & $0 \%$ & $0 \%$ & $0 \%$ \\
AD & $50 \%$ & $24 \%$ & $18.18 \%$ & $0 \%$ & $0 \%$ & $0 \%$ \\
\hline
\end{tabular}

As we can see, when a subject had difficulty with a cluster A (A is the difference in sonority between the segments), then she/he also had difficulty with clusters of SD A-1.

Thus, an error in clusters with an SD of 4 (e.g., [b^lb] $\rightarrow[b \wedge l]$ implied errors in sequences with an SD of 3 (e.g., [memba.z] $\rightarrow$ [membar]), an SD of 2 (e.g., [muvd] $\rightarrow$ [muv]), and an SD of 1 (e.g., [drimz] $\rightarrow$ [drim]), but not vice versa. Based on these findings, the claim regarding the unmarked nature of clusters with greater SD is supported. However, the errorless production of clusters with greater minimal sonority distances (MSD) of 5 and 6 does not imply the correct production of clusters of smaller MSD $(4,3,2,1)$.

Table 8 Mean \% of correct productions made by each subject per each value of sonority distance

\begin{tabular}{lllllll}
\hline Subject ID & SD1 & SD2 & SD3 & SD4 & SD5 & SD6 \\
\hline & $11.11 \%$ & $32 \%$ & $36.36 \%$ & $63.63 \%$ & $100 \%$ & $100 \%$ \\
JC & $0 \%$ & $22.72 \%$ & $25 \%$ & $63.63 \%$ & $100 \%$ & $100 \%$ \\
LW & $12.50 \%$ & $41.66 \%$ & $72.72 \%$ & $75 \%$ & $100 \%$ & $100 \%$ \\
LC & $12.50 \%$ & $15 \%$ & $20 \%$ & $63.63 \%$ & $100 \%$ & $100 \%$ \\
RB & $12.50 \%$ & $22.72 \%$ & $36.36 \%$ & $45.45 \%$ & $100 \%$ & $100 \%$ \\
CF & $0 \%$ & $26.92 \%$ & $27.27 \%$ & $33.33 \%$ & $100 \%$ & $100 \%$ \\
IF & $0 \%$ & $36 \%$ & $36.36 \%$ & $40 \%$ & $100 \%$ & $100 \%$ \\
AD & & & & & \\
\hline
\end{tabular}

The data in Table 8 reveals that when the subject's production of clusters with an MSD of 5 and 6 was errorless, it did not mean that the same subject did not have any difficulty 
producing clusters with an MSD of $1,2,3$, or 4 . This fact also confirms the claim regarding the hierarchy of difficulty: the acquisition of the more difficult, more marked structures implies the acquisition of the less marked structures. Because the SD decreases going from flap + stop (e.g., /rk/ from 7 ro 1 ) to flap + fricative (e.g., /rs/ from 7 to 3 ), to flap + nasal (e.g., /rn/ from 7 to 5), and then to flap + liquid (/rl/ from 7 to 6$)$, a language without these coda clusters would find them increasingly less natural and more laborious. As we know, Spanish does not allow for cluster complexity in word-final codas, so it is assumed that this language has a coda setting (minimal sonority distance) of 5 . Hence, there are few or no transfer effects in the production of complex codas by ESL Spanish speakers. Eleven out of fifteen subjects had no errors at all in words with clusters having an MSD of 6. Only 5 subjects employed a substitution of sound (final obstruent devoicing) in these words. For example, Subject CP substituted $/ \mathrm{t} / \mathrm{for} / \mathrm{d} / \mathrm{in}$ 'forward' which can be explained by the universal nature of devoicing word-final obstruents.

Sonority distance of 0

Clusters with the sonority distance of 0 between their segments are as follows: voiceless stop + voiceless stop: $/ \mathrm{pt} /, / \mathrm{kt} /$, voiced stop + voiced stop: $/ \mathrm{bd} /, / \mathrm{gd} /$, voiceless fricative + voiceless fricative: $/ \theta \mathrm{s} /, / \mathrm{fs} /, / \mathrm{f} \theta /$, voiced fricative + voiced fricative: $/ \mathrm{vz} /$ ). Since both segments in this group of clusters have identical sonority values (e.g., $/ \mathrm{pt} /$ from 1 to 1 , /bd/ from 2 to 2 , /fs/ from 3 to $3, / \mathrm{vz} /$ from 4 to 4 ), it seems reasonable to analyze them separately, instead of with other groups. The CC sequences in this group do not have any sonority distance between their members. The majority of subjects (11 out of 15$)$ made substitutions in the form of final obstruent devoicing in morphologically complex words: 
[livz] as [livs], [gIvz] as [gIvs], [gl^vz] as [gl^vs]. One subject, $\mathrm{AN}$, reduced the above-mentioned clusters: [gIVz] as [gIv]. It is difficult to account for this phenomenon, because both segments have an MSD of 0 (basically, no distance at all). In the case of morphologically complex words such as [mauðs], [læfs], [fif $\theta]$, [snIfs], the reduction of word-final coda clusters was more frequent than the simple substitution of segments (11 out of 15 - reduction of $\mathrm{C} 2:[\mathrm{læf}] \rightarrow[$ læf $],[$ fife] $\rightarrow$ [fif], [snIfs] $\rightarrow$ [snIf]). Two subjects employed a substitution in [mauðs] as [mauts].

In word-final codas consisting of two stops together such as [əksept], [kukt], [ræpt], [klogd], [robd] the picture is a little bit different. Subjects used both processes: devoicing and reduction. The process of reduction was observed mostly in words such as: $[\mathrm{kukt}] \rightarrow[\mathrm{kuk}]$ (3 subjects out 15$),$ [græbd] $\rightarrow$ [græb], [robd] $\rightarrow$ [rob], $[\mathrm{klogd}] \rightarrow[\mathrm{klog}]$ ( 5 out of 15 ). However, some subjects employed final obstruent devocing in such words as [græbd] $\rightarrow$ [græbt] or [græpt], [robd] $\rightarrow$ [robt] or [ropt], $[\mathrm{klogd}] \rightarrow[\mathrm{klogt}](3$ out of 15$)$

In clusters with two obstruents, where the second member was a coronal sound such as $/ \mathrm{pt} /, / \mathrm{kt} /, / \theta \mathrm{s} /$, subjects deleted the coronal. Coronal sounds are "...sounds that are produced with the front part of the tongue raised from the neutral position" (Yavas, 1998, p.73). Dental/alveolar, palato-alveolar, retroflex, palatal sounds are examples of coronal segments. The word [kukt] was realized as $[\mathrm{kuk}]$ (not * [kut]) in all the cases where there was an incorrect production. The word [əksept] was also realized as [əksep] (not as * [ekset]). 
The words [rəd $3 \varepsilon \mathrm{kt}]$ and [ræpt] underwent the following modifications accordingly:

$[\mathrm{r} \partial 3 \varepsilon \mathrm{k}]$ and $[\mathrm{r} p]$.

Sonority distance of 1

The following sequences belong to this division: nasal + voiced fricatives: $/ \mathrm{nz} /, / \mathrm{mz} /$, liquids + nasals:-/1m/, flap + liquid: /rl/. Eight out of fifteen subjects produced a deletion of the $\mathrm{C} 2$ in sequences such that [koInz] $\rightarrow[$ koIn], [penz] $\rightarrow[p \varepsilon n],[p I n z] \rightarrow[p I n]$, $[$ drimz $] \rightarrow[$ drim $]$, [blumz $] \rightarrow$ [blum], and [grumz $] \rightarrow$ [grum].Seven out of 15 subjects produced a substitution in the form of final obstruent devoicing in these sequences (e.g., a voiceless fricative for its voiced counterpart).

Most likely, due to the effect of $L 1$ transfer, subjects reduced the flap $/ r /$ in the sequence $/ \mathrm{rl} /$. For example, $[\mathrm{k} 3 \mathrm{rl}] \rightarrow[\mathrm{k} 3 \mathrm{l}]$, and $[\mathrm{p} 3 \mathrm{rl}] \rightarrow[\mathrm{p} 3 \mathrm{l}]$. As we know, Spanish allows a liquid /1/ in a single C coda: 'papel'.

Surprisingly, the majority of subjects (10 out of 15$)$ produced a reduction of the liquid in the sequence liquid + nasal $/ \mathrm{lm} /:[\mathrm{fIlm}] \rightarrow[\mathrm{fIm}]$. As per the SSP, the subjects should have reduced the nasal (a sound with a lesser sonority value as compared to the liquid) in order to provide a minimal sonority descent (e.g., [fIlm] $\rightarrow[\mathrm{f} I \mathrm{l}])$. However, this is not the case based on our data. This is also a very peculiar phenomenon since it cannot be explained in terms of L1 transfer, because Spanish does not permit $/ \mathrm{m} /$ as its single coda. The only nasal that can occur in the final position is $/ n /$ in the word 'pan'. This fact can, probably, be explained by the assumption that since liquids are more sonorous elements than nasals, they are perceived as belonging to the nucleus: 
Figure 1. Syllable structure of the word 'film' where $/ /$ is considered to belong to the nucleus

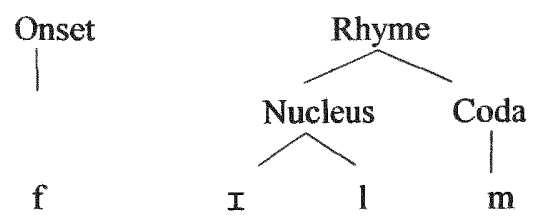

So, basically, we can assume that Spanish speakers perceive such sequences as single $\mathrm{C}$ codas rather than two-member codas. Hence, no reduction takes place. However, other factors may account for the simplification of final consonant clusters. One contributing factor such as ease of perception may be relative; liquids are acquired much later than nasals. As has been noted, some sounds are intrinsically more difficult to pronounce than others due to a more elaborate series of articulatory gestures. Table 9 below shows the order of acquisition of consonants with respect to ease of articulation:

Table 9 Acquisition of consonants with respect to ease of articulation

$\mathrm{n}>\mathrm{mphfwg}>\mathrm{tkbgs}>\mathrm{yd}>\mathrm{lr}>\mathrm{t} \iint \mathrm{d} 3>\mathrm{v}>\mathrm{z} z>\theta \delta$

But if this were true, then according to the Articulatory Ease Hypothesis, subjects should reduce clusters to whichever segment is easier to pronounce. Thus, the word 'reject' should be reduced to [rəd $3 \varepsilon t]$ since $/ t /$ is easier to pronounce than $/ \mathrm{k} /(/ \mathrm{t} /$ is acquired earlier than $/ \mathrm{k} /$ ). However, this is not the case, and the data confirms this fact; no subject reduced the cluster in this way. No matter how enticing this theory seems to be, it fails to explain why sounds that are considered easy to perceive are omitted in favor of less perceptible sounds in some cases. The cohesion of liquid codas with nucleus vowels was the subject of a study by Treiman (1989) which indicated that rhymes containing a sequence of a vowel plus an obstruent (e.g., /at/) were easier to segment into phonemes than strings containing a vowel plus liquid or nasal. This seems to suggest that the ease of 
segmentation depends upon the degree of difference in sonority between the coda consonant and the preceding vowel.

Yavas \& Gogate (1999) explored the impact of sonority on coda consonant deletion as observed in the speech of monolingual first graders. The stimuli consisted of 16 monosyllabic words with non-low tense vowel and different coda consonants (stops, fricatives, nasals, and liquids). The children were asked first to pronounce the words, and then to delete the final consonant and say the remaining word. The results of the study provide further support to the idea that segmentation accuracy increases with sounds of lower sonority and decreases with an increase in the sonority of phonemes. A greater number of errors were observed in sequences containing liquids (more sonorous segments).

Another study by Yavas \& Core (2001) investigated the effect of sonority on segmentation as observed in the speech of bilingual Spanish/English first graders. In spite of the fact that Spanish allows nasals and liquids as singletone coda consonants, Spanish-speaking children made more errors when producing liquids and the fewest when producing stops. The results indicated that the number of errors for each coda type followed the sonority hierarchy.

Paolillo (1995) studied the acquisition of English liquids $/ 1 /$ and $/ \mathrm{r} /$ by speakers of Mandarin. Mandarin contrasts these two sounds only in syllable-initial position while English has a contrast of $/ 1 /$ and $/ r /$ in any syllable position. It was found that the acoustic perception of liquids is more salient in initial position or as a syllabic consonant than in clusters (post vocalic position). The findings support the assumption that due to a vocalic nature, liquids are very difficult to separate from the nucleus. Thus, subjects seem to treat 
them as single units. The data of the experiment proves this idea. These findings also confirmed the idea that the difficulties learners encounter cannot be explained solely on the basis of their NL. One has to consider the effect of universal markedness on a given sound in a particular environment.

Sonority distance of 2

The sequences composed of a voiceless fricative + a voiceless stop: /st/,/sk/, /ft/,/st/; voiced fricative + voiced stop: $/ \mathrm{zd} /, / \mathrm{vd} /, / \partial \mathrm{d} /$; nasal + voiceless fricative: $/ \mathrm{n} \theta /, / \mathrm{ns} /$; liquid + voiced fricative: $/ \mathrm{lv} /, / \mathrm{lz} /$, and flap + nasal: $/ \mathrm{mn} /, / \mathrm{rm} /$. These sequences have the sonority distance value of 2 between their segments. The sequence /ns/ was realized correctly in 15 out of 15 cases. This fact can be possibly explained by the presence of such clusters word-internally in Spanish as, for example, in the word "construir". However, when subjects had to deal with the sequence nasal + interdental voiceless fricative $/ \mathrm{n} \theta /$, the picture was quite different. What we see here is that 5 subjects out of 15 produced the correct word $[\mathrm{m} \wedge \mathrm{n} \theta], 3$ subjects deleted the second segment $/ \theta /$. Seven subjects employed substitutions as follows: $1-[\mathrm{m} \wedge n \theta] \rightarrow[\mathrm{m} \wedge \mathrm{ns}], 5-[\mathrm{m} \wedge n \theta] \rightarrow[\mathrm{m} \wedge n t]$.

As mentioned already, the only final obstruent allowed in Spanish is the phoneme $/ \mathrm{s} /$. Hence, this phenomenon of substitution of the sequence $/ \mathrm{ns} /$ for $/ \mathrm{n} \theta /$ can be ascribed to the effect of transfer from the L1. However, the substitution of $/ \mathrm{nt} /$ for $/ \mathrm{n} \theta /$ cannot be accounted for in the same way. Subjects modified this sequence in such a way as to achieve greater SD between the segments of the consonant cluster in favor of the least marked string(e.g., /nt/ from 5 to 1 for $/ \mathrm{n} \theta /$ from 5 to 3 ). This modification is in full compliance with minimal sonority descent. This analysis supports the claim that L1 does 
not play a crucial role in shaping the phonology of L2 speakers. Universal developmental factors are at work here. Otherwise, we would expect all Spanish subjects to employ the sequence /ns/ in all cases as Spanish allows it word-internally. It has to be mentioned that in the case of /ns/ the MSD is 2, and in the case of /nt/, the MSD is 4. Everything mentioned above provides further proof of the universal nature of the SSP acting independently of the L1.

Seven out of 15 subjects employed a substitution in the form of final obstruent devoicing of the second segment in the sequence such as /zd/, for example $[\mathrm{kozd}] \rightarrow[\mathrm{kozt}]$. All subjects substituted a voiceless stop for its voiced counterpart (final obstruent devoicing). Interestingly, 7 out of 15 subjects deleted the second segment of the string composed of a voiced interdental fricative + voiced stop from $/ ð \mathrm{~d} / \mathrm{to} / \mathrm{\sigma} /$, and substituted $/ \theta /$ or $/ \mathrm{s} /$ for $/ \mathrm{\partial} /$. Consequently, two repair strategies took place simultaneously: [bri $\theta]$ or [bris] for [briðd]. After the second segment is deleted, the subjects are left with [brið]. But voiced obstruents are marked word-finally, and Spanish does not allow any obstruents except $/ \mathrm{s} /$ at the end of the word. Hence, final devoicing occurs.

Nine out of 15 subjects substituted a voiceless stop for the second segment of the

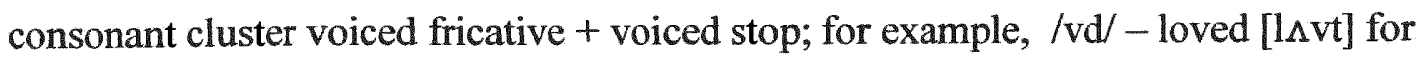
[lıvd], moved [muvt] for [muvd]. Two subjects deleted the sound /d/ in $[$ muvd] $\rightarrow$ [muv]. Another group of morphologically complex words are represented in examples with clusters of liquid + voiced fricative such as $/ \mathrm{lv} /, / \mathrm{z} /$. In this case, the majority of the subjects employed final obstruent devoicing replacing $/ \mathrm{s} /$ and $/ \mathrm{f} /$ for $/ \mathrm{z} /$ 
and $/ \mathrm{v} /$ in the consonant clusters such that $/ \mathrm{lz} / \rightarrow / \mathrm{ss} /, / \mathrm{v} / \rightarrow / \mathrm{lf} /$. In the case of clusters composed of liquid + nasal, all subjects deleted the first segment thereby retaining the second segment of lesser sonorance; for example [13rn] $\rightarrow[13 \mathrm{n}]$. It is worth noting that these are the only two cases in the data when subjects deleted the first segment of the consonant cluster and not the second one. The most plausible explanation for this is that Spanish ESL speakers perceive flaps and liquids as constituents of the nucleus of the syllable, not the coda (See earlier discussion.).

Sequences /st/ and /sk/ in [test] and [æesk] were realized correctly in 11 out of 15 cases. Four subjects deleted the coronal sound (stop) in this sequence (i.e. $[t \varepsilon s t] \rightarrow[t \varepsilon s])$. Another group of clusters composed of the word-final alveolar stop $/ t /$ preceded by a voiceless fricative as in $[\mathrm{gIft}],[1 \varepsilon \mathrm{ft}],[\mathrm{mIst}],\left[\mathrm{pv} \int \mathrm{t}\right],[\mathrm{kIst}]$ underwent the following modifications: 11 out of 15 subjects deleted the final segment in the clusters $/ \int \mathrm{t} /, / \mathrm{st} /$, and $/ \mathrm{ft} /$. For example, [gIft] $\rightarrow[\mathrm{gIf}],\left[\mathrm{pv} \int \mathrm{t}\right] \rightarrow\left[\mathrm{pv} \int\right],[\mathrm{kIst}] \rightarrow[\mathrm{kIs}]$, $\left[\mathrm{kæSt}\left[\rightarrow\left[\mathrm{kæ} \int\right]\right.\right.$. Interestingly, the word [left] with the cluster $/ \mathrm{ft} /$ was not modified by 12 out of 15 subjects; the familiarity of this word could be a contributing factor to its non-modification. Three subjects deleted the final coronal stop in the word 'left' (e.g., $[1 \varepsilon f t] \rightarrow[1 \varepsilon f])$.

\section{Sonority distance of 3}

The sequences containing nasal + voiced stop: /nd/; liquid + voiceless fricative: /ls/, /lf/; flap + voiced fricative: / $\mathrm{rz} /$ possess final codas with the sonority distance of 3 . The data revealed that subjects produced a very high number of substitutions in clusters composed of a nasal + a voiced stop /nd/ and a flap + a voiced fricative / rz/, which is not surprising 
due to the presence of voiced obstruents in the marked word-final position. In these sequences, 11 out of 15 subjects replaced the second segment of the cluster: a voiced stop was modified into its voiceless counterpart (e.g., $/ \mathrm{nd} / \rightarrow / \mathrm{nt} /, / \mathrm{rz} / \rightarrow / \mathrm{rs} /$ ). Four subjects deleted the final voiced fricative in these sequences (e.g., [onz.z] $\rightarrow$ [onz]). All substitutions involved eliminating the more sonorous second segment in favor of a segment with less sonority, therefore increasing the sonority distance between the two segments of the consonant cluster. In the sequences of liquid + voiceless interdental fricative ([hel0]), 2 out of 15 subjects deleted the interdental fricative $/ \theta /$, and 4 out of 15 replaced this sound with the alveolar stop $/ t$, thereby increasing the minimal sonority distance between the segments from 3 to 5 . This phenomenon operated independently of L1 transfer. As already mentioned, Spanish does not allow obstruents word-finally except for $/ \mathrm{s} /$.

Sonority distance of 4

The following sequences represent clusters with this sonority distance between their members: nasal + voiceless stop: $/ \mathrm{mp} /, / \mathrm{nt} /, / \eta \mathrm{k} /$; liquid + voiced stop: /lb/, /ld/; flap + voiceless fricative: /rs/. Eleven out of 15 subjects produced no errors in clusters of a nasal + a voiceless stop, and a flap + a voiceless fricative. At the same time, however, the same 11 subjects had problems with the sequence liquid + voiced stop. Eleven out of 15 subjects replaced the voiced sound with its voiceless counterpart. All these examples point out the universal nature of the phonological process of final devoicing. Four out of 15 deleted the flap $(\mathrm{C} 1$ of $\mathrm{CC})$ in the sequence $/ \mathrm{rs} /:$ for example, [n3rs] $\rightarrow$ [n3s]. 
The sequences are: liquid + voiceless stop: $/ \mathrm{lt} /, / \mathrm{k} /$, and flap + voiced stop: $/ \mathrm{rd} /$.

Since clusters with these sonority values are considered to be the least marked, or in other words, more natural as per SSP, it seems reasonable to analyze them together. Generally, no subjects produced errors in codas where the sonority distance between segments was 6 . Only 5 out of 15 subjects replaced a voiced stop with its voiceless counterpart; for example, [rd] for [rt]. Overall, these findings support a correlation between the number of errors produced and the minimal sonority distance between the members of complex coda clusters. The larger the MSD, the fewer the errors produced. 


\section{CHAPTER V}

\section{Discussion}

\section{Types of errors}

If we look at syllable structures cross-linguistically, we will see that syllables tend to prefer onsets rather than codas in order to conform to the Universal Canonical Syllable Shape (CV). This idea is reflected in the Onset Maximization Principle, which states place the syllable boundaries in such a way that onsets are maximized without violating the syllable structure conditions of the language. (Yavas, 1998, p. 242).

It can also be stated that onsets are preferred over codas cross-linguistically. Anderson (1987) found that onsets are less frequently modified than codas. The Chinese subjects she dealt with modified less than $1 \%$ of all onsets, but over $20 \%$ of all codas. ESL speakers tend to modify coda clusters in different ways, and some of the processes they use are independent of their L1. It has to be stated that simplification strategies used by ESL speakers differ with respect to codas and onsets. While epenthesis is widely attested to as one of the primary error types produced by learners in relation to onsets, deletion of one of the segments of the consonant cluster, or substitution of one of the segments of the $\mathrm{CC}$ are primary strategies that ESL speakers use when attempting complex coda clusters. As we know, the most unmarked type of the onset cluster consists of a steep rise in sonority between the onset and the nucleus of the syllable. Thus, in the case of two-consonant onsets, epenthesis is the optimal repair strategy; for example, [pley] is realized as [piley]. In such a case i-insertion provides a sharp rise in sonority, which is in full compliance with the SSP. The opposite process is going on in codas: the most unmarked, natural type of coda is one with a minimal sonority descent between the 
nucleus and the coda; for example, [dark] is less marked than [b^lk]. This is why in order to produce the least marked coda, learners delete the least sonorous segment, and thus create a minimal sonority descent between the nucleus and the coda; for example, $([p I n z] \rightarrow[p I n])$. Alternatively, substitution of one of the segments is employed in order to achieve greater sonority distance between the two members of the complex coda; for example, [bulz] $\rightarrow$ [buls]. The results of the experiment confirmed this idea. Three main modification methods were used by Spanish ESL speakers when attempting the complex CC codas of English:

1. Deletion of one of the segments of the consonant cluster.

2. Final obstruent devoicing.

3. One of the segments was replaced by another having a different place of articulation.

In only two cases, in sequences composed of a liquid + nasal (e.g., $/ 1 \mathrm{~m} /)$ and a flap + a nasal (e.g., /m/), did subjects delete the first segment of the CC. In all other consonant strings they deleted the second segment of the consonant cluster.

Another process that was ubiquitous in this data was final obstruent devoicing. Generally, this process is observed with voiced stops, fricatives, and affricates, but in some cases it is restricted to stops. Voicing contrast of obstruents is attested to in many languages of the world. However, the position of the obstruent within the word plays a crucial role. Yavas (1997) mentions that while English allows voiced and voiceless stops in all positions within a word, other languages such as Russian, Turkish, German, etc. restrict the voicing contrast to the word-initial and word-medial position. One cannot find 
voiced stops in final position in these languages. The same process occurs in the speech of ESL speakers. When speakers of Russian, Turkish, or Polish study English, one can explain the nature of this phenomenon in terms of L1 transfer. However, this process also occurs with ESL speakers whose native languages do not allow any stops in final position, e,g. Spanish, Mandarin Chinese, etc. Eckman (1981) demonstrated the L1independent nature of this process in the ILs of Cantonese and Spanish learners of English. Major (1987) writes: “...the fact that this process cannot be attributed to the $\mathrm{NL}$ of the speakers...is evidence that it reflects the innate speech capacity of the human organism" (p. 211).

Some of the researchers found a correlation between the place of articulation of the final stop (its propensity for devoicing), and the role of the height of the preceding vowel. Yavas (1997) investigated these two factors with ESL speakers of Mandarin Chinese, Japanese, and Portuguese. He found that subjects tended to employ more devoicing with bilabial stops, than with alveolar and velar stops. More devoicing was observed in cases where the preceding vowel was high. The reason for this is that high vowels create more constriction within the vocal tract by raising the tongue, which in turn creates more supraglottal pressure. As was described earlier in the analysis of the data from this experiment, final obstruent devoicing was one of the strategies that ESL Spanish speakers used in order to increase minimal sonority distance (MSD) between the two members of complex codas. The nature of this process is universal and does not seem to depend upon the sonority values of individual segments in a given consonant cluster. The marked nature of the voiced obstruent at the end of the word plays a crucial role. 
Replacing the second segment of the consonant cluster with another segment differing in place or manner of articulation was another strategy that ESL Spanish speakers used to modify coda clusters. But, unlike the processes of cluster reduction or final obstruent devocing, this phenomenon was quite rare: only two subjects replaced the interdental $/ \theta /$ with $/ t /$ and thereby converted the cluster $[\theta$ s] to $[\mathrm{ts}]$. The manner and place of articulation are different; $/ \theta /$ is an interdental fricative, while $/ t /$ is an alveolar stop. Obviously, this is a case of so-called stopping of fricatives, and this substitution cannot be explained in terms of NL transfer since Spanish does not permit any obstruents in final position except/s/. Even though the newly formed cluster violates the SSP (that is /ts/ from 1 to 3 ), it is still less marked than the target sequence $/ \theta \mathrm{s} /$ by virtue of the universal nature of $/ \mathrm{t} /$.

One more case of such a replacement also occurred in sequences containing the interdental fricative. The cluster [n $\mathrm{n} \theta$ ] with a MSD of 2 conceives such an example: seven subjects replaced the interdental fricative with another sound: 1 with $/ \mathrm{s} /-/ \mathrm{n} \theta / \rightarrow / \mathrm{ns} /$, five with $/ \mathrm{t} /-\ln \theta / \rightarrow / \mathrm{n} t /$. All resulting sequences are less marked that the target ones and contain $/ \mathrm{s} /$ and $/ \mathrm{t} /$ as second segments.

\section{Place of articulation and its effect on errors}

The question of the correlation between sonority and place of articulation has not been so widely discussed in the literature as the concept of sonority itself. While there is at least some agreement about the role of sonority in syllabification, the role of the place of articulation and its connection to sonority is very controversial. This originates from the fact that up to now there has been no agreement among phonologists as to exactly what the universal sonority hierarchy consists of. Steriade (1982) claims that the feature 
[coronal] has to be included in the universal sonority scale as initial sequences such as $/ \mathrm{tl} /, / \mathrm{d} \mathrm{l} /$ are not permitted in languages cross-linguistically. Under this assumption, $/ \mathrm{t} /$ and $/ \mathrm{d} /$ are closer in sonority values to $/ 1 /$ than are the noncoronals (e.g., $/ \mathrm{pl} /, / \mathrm{kl}$ ), and therefore, are found not permissible under the Minimal Sonority Distance constraint. As Selkirk (1984) notes, we must assign coronals a higher rank in sonority in order to explain the phenomena found in Spanish and Italian where only sonorants and coronal /s/ are allowed in final position. But as Clements points out, even one and the same language can treat coronals in different way, and there is a great deal of inconsistency in the area of coronals. They pattern peripherally to initial and final obstruent clusters (apt, accept, reject). He argues that in English, coronals can occur at the margins of the syllable (e.g., $/ \mathrm{pt} /$ in 'opt', $/ \mathrm{ks} /$ in speaks, /fs/ in 'laughs'), and this fact suggests that they must have lower rank on the sonority scale than noncoronals (in compliance with the SSP). On the other hand, some facts from English can provide evidence to the claim that coronals have higher rank on the sonority scale. For example, /s/ and /z/ are only coronals that can precede a noncoronal stop in the word like 'whisper', 'lisp', 'ask'. In my data I tried to look at such clusters to see whether the coronals in reality can be considered as having a higher rank in sonority than noncoronals. My goal was to look at the process of reduction in sequences such as voiceless stop + voiceless stop, voiced stop + voiced stop, voiceless fricative + voiceless fricative, and voiced fricative + voiced fricative. The second segment in these clusters is a coronal sound: $/ \mathrm{pt} /, / \mathrm{kt} /, / \mathrm{bd} /, / \mathrm{gd} /, / \theta \mathrm{s} /, / \mathrm{fs}, / \mathrm{vz} /$. If it is true that coronals have a higher sonority value than noncoronals, then we can assume that they will be retained by the subjects when they deal with complex codas. As we know, the more sonorant segments are less marked in codas. The above-mentioned sequences 
would be reduced in the following way: [kvkt] 'cooked' to [kvt], [əksspt] 'accept' to [əkset], [braIbd] 'bribed' to [braId], [klogd] 'clogged' to [klod], [snIfs] 'sniffs' to [snIs], [læfs] 'laughs' to [læs], [gIvz] 'gives' to [gIz]. However, this is not the case; as no subjects produced such types of reduction. For this reason, I would like to argue that it seems unreasonable to introduce a special subdivision for coronals on a sonority scale in order to accommodate a place of articulation. I would, probably, agree with another idea that anterior coronals occur more freely in clusters than do other consonants; they can be either the first or the second segment in the clusters. This fact can be attributed to the individual characteristics of anterior coronal sounds. But, in any case, sonority and place of articulation show different properties within syllables as well as across syllables. L1 transfer and its effect on the acquisition of ESL codas by Spanish speakers

As is well-known, L1 transfer can operate on those segments that are similar in both the L1 and L2. Flege (1987) introduces the term "equivalence classification". These classifications usually result in the positive transfer of elements from the $\mathrm{L} 1$ into the IL of the ESL speaker. This accounts for the substitution of the voiceless fricative /s/ in place of $/ z /$ in the sequence $/ \mathrm{nz} /$. The resulting cluster was realized as $/ \mathrm{ns} /$. As was pointed out earlier in this chapter, Spanish does not allow complex codas word-finally, and the only obstruent that can occur as a singletone coda is the sound /s/. Word-internally, however, Spanish permits strings such as /rs/ as in 'perspicaz', or [ns] as in 'monstruo'. The only relatively strong sequence is $/ \mathrm{ns} /$; which is not deleted as often as all other word-internal $\mathrm{CC}$ clusters. This is why we can attribute a very high number of substitutions in this sequence to positive transfer from the L1. Overall, this effect of transfer is not pivotal. 
Presumably, the Spanish language has a setting for the minimal sonority distance of 5 (since the largest allowable difference between consonant-like segments is 4 ; from a glide $/ y /$ with the SD of 5 to a voiceless stop /t/ with the SD of 1 ), because it does not allow any complex codas word-finally, and has a very scarce number of word-internal CC codas. The conjecture is that there will not be large transfer effects in complex L2 codas for the speakers of Spanish. The results of this study proved this fact to be true. This idea can also account for the fact that clusters with smaller sonority distance should be more difficult to acquire for Spanish ESL speakers. As we can observe, the data of the experiment supports this prediction. More reductions and the least number of correct realizations occurred in clusters with the smallest SD of 1 . Based on everything mentioned above, we can state that in addition to the small extent of L1 transfer, other universal developmental processes were at work when subjects attempted complex English codas. These include final consonant cluster reduction (in full compliance with the SSP), final obstruent devoicing. These processes can be in no way ascribed to transfer from the speakers' L1 (Spanish does not permit complex codas, and it does not allow any obstruent word-finally except $/ \mathrm{s} /$.). These phenomena can be found in many other languages of the world. The relationships between $\mathrm{L} 1$ transfer and the universal developmental factors are very complicated. Major (1987) claimed that IL consists of the following components: L1, L2, and universals. He proposed the Ontogeny Phylogeny Model (OPM), which conceives the basic pattern of development for the IL: L2 increases, L1 decreases and universals increase and then decrease. But the picture of the developing phonology of bilingual speakers is even more complicated by such factors as the age of the learner, age of arrival in the country where the L2 is studied, and the 
dominance of one language over the other. All these data together with universal developmental factors effecting second language acquisition have to be taken into account.

Age of Learning. Early versus late bilinguals

As 7 out of 15 subjects taking part in this experiment were so-called early/simultaneous bilinguals whose ages of arrival in the USA varied from 3 months up to 10 years of age, the issue of AOL along with the length of stay in the community became very relevant. The data in Table 6 show that, overall, the mean percentage of correct production for early versus late bilinguals differs to some extent in all groups of clusters with different SDs. Early or simultaneous bilinguals performed better than the late ones. How can we account for this fact? Researchers in the field of L2 acquisition have noticed that some bilinguals seem to be able to achieve a nativelike performance in phonology while others are not. Moreover, the larger number of such individuals can master syntax, morphology, and all other aspects of the language, but not phonology. In the case of immigrant families, it is very common that children acquire L2 phonology in a nativelike manner, while their parents do not. There have been a number of studies done to this regard. It has been suggested that there is a period from birth until puberty during which the phonological system of the L2 language can be acquired natively. After puberty, this ability appears to decrease. Thompson (1991) investigated a wide variety of factors including age of arrival (age of learning), length of stay, sex, motivation, etc. and found age of learning to be the most pivotal factor affecting the learner's accent.

Oyama (1976) found a strong relationship between the age of arrival (age of learning) and accent of 60 Italian immigrants. Based on the results of the data, we can 
confirm the age of learning (age of arrival) as one of the strongest factors affecting the performance of our early/simultaneous bilingual subjects in this study. As we can see from the data in Table 6, the number of correct productions for each SD is higher for the early bilinguals than it is for the late ones. The small difference between the number of correct productions between early and late bilinguals can, probably, be attributed to the claim of monitoring and individual variation between subjects. Individual differences in talent, genetics, psychological, and social factors and many other causes can influence the learner. Different cases of monitoring are introduced by (Major, 2001). He talks about hypomonitors and hypermonitors. A hypomonitor is the learner who monitors so poorly, that L2 progresses very slowly. A hypermonitor monitors so much that $U$ predominates, and at the same time the amount of L2 increases rapidly. Major (2001) claims that the more monitoring, or the more formal style is, the greater the accuracy. Hence, in a more formal situation, more monitoring occurs. Subjects in our data have been required to read words written on flash cards (this type of data can be treated as formal). The issue of individual variation together with the factor of monitoring can at least partially explain the small difference in the number of correct productions between early and late bilinguals in our data. It has been noticed that variation exists on all levels of language, in the syntax, lexicon, morphology, semantics, pragmatics, and phonology. There are numerous individual factors that affect L2 phonology. They include motivation, risk-taking, self-esteem, sense of identity, etc. Motivation is considered to be one of the pivotal factors for all aspects of success in L2 acquisition, not only phonology. But even if the learner is strongly motivated to learn a language there are other personality factors that can prevent success, such as anxiety, lack of empathy, and low ego permeability. 
One of the explanations of better performance by early/simultaneous bilinguals may be the fact that the stages of acquisition for early/simultaneous bilinguals differ. Major states that in initial stages for adult L2 learners, the influence of L1 is so strong that it prevents universals $(U)$ from exerting their influence (see Figure 2).

Figure 2. Stage 1. Adult L2 learners. Unmarked phenomenon.

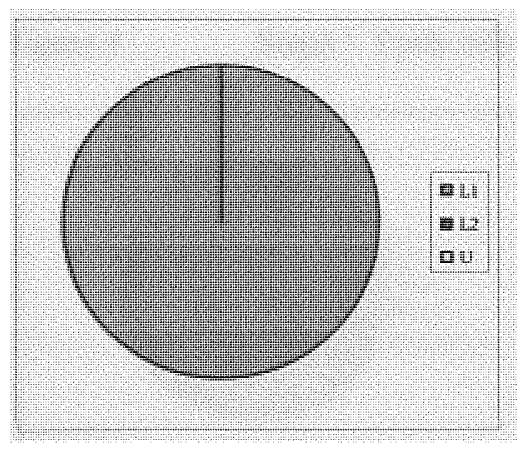

In the case of these subjects, it has already been noted that the effect of transfer was not significant, as Spanish does not allow complex codas word-finally. Hence, universal developmental factors (U) take over and are seen in the form of consonant cluster reduction and final obstruent devoicing, as attested to by the current data. In the case of the marked phenomenon, the relative proportion of $U$ is higher on early stages as compared to the unmarked (See Figure 3.).

Figure 3. Stage 6. Adult L2 learners. Marked phenomenon.

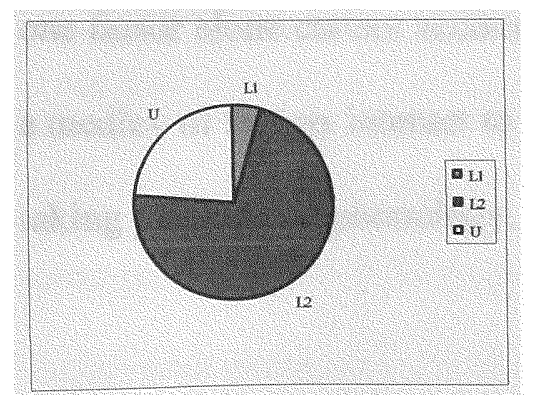

As the author mentions, however, this claim applies to the whole IL system, but the relative proportions of $\mathrm{L} 1, \mathrm{~L} 2$, and $\mathrm{U}$ at any given stage depend also upon the individual 
learner and the phenomena studied. For example, in the case of the acquisition of more marked phenomena (e.g., final coda clusters by Spanish ESL speakers), the relative proportion of L 2 can be very insignificant over a longer period of time. During Stage 1 of simultaneous bilingual acquisition, the child starts with $U$ as in $L 1$ acquisition, but she/he is concurrently exposed to two languages (See Figure 4.).

Figure 4 Stage 1. Early bilingual learners. OPM

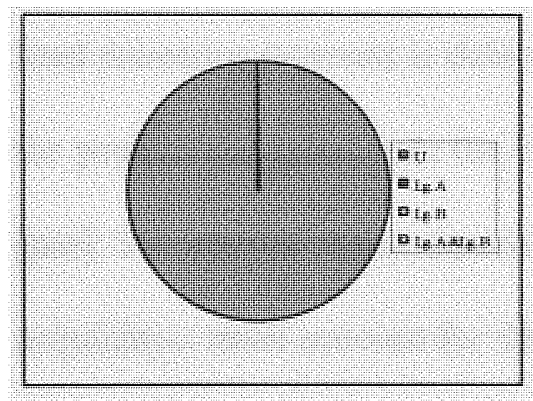

In this first stage, the child has one undifferentiated system. At a later stage, these systems become separate. Of course, this implies an idealized learner, whose systems eventually become separate and equal. Hence, the difference in stages of acquisition for early versus late bilingual subjects can account for the difference in their overall performance. Since the starting point is very different for early bilinguals versus late ones, the former start with $U$, while the latter with L1. As we see from the discussion, one factor alone cannot account for the complexity of L2 phonological acquisition; rather a medley of factors interact to provide a plausible explanation for different processes taking place in L2 phonology. 


\section{Conclusion}

The Sonority Hypothesis is based on the notion that a specific relationship exists between the segments in complex coda clusters cross-linguistically. Methods of complex coda clusters modifications used by children acquiring their L1, bilingual children, patients with phonological disorders, and adult ESL speakers are all very similar. They tend to delete one of the segments of the complex coda in compliance with the SSP (the least sonorous segment is deleted in order to achieve the minimal sonority descent from the peak of the syllable to the following segment). For example, [park] can be reduced to [par]. The results of the experiment confirmed this claim. Thus, a theory of phonological acquisition must account for these intrinsic relationships.

The results of this thesis can have far-reaching implications in the teaching of L2 phonology. The last of the three groups are subjects (patients with phonological disorders and second-language learners) for whom the mastery of the second language is the pivotal issue. Thus, assuming that sonority is the crucial and strong factor in the IL phonology as well as in other developing phonologies, there has to be much more attention paid to the use of the findings in second language acquisition studies in the teaching of English as a second language, preparation of materials, etc. The findings show that difficulties ESL speakers encounter in pronunciation depend crucially upon the position of the segment in the syllable. Because codas are more restricted than onsets, more problems are to be expected with codas rather than with onsets. Hence, the teaching assignment exercises have to focus more on codas rather than just simply on segments occurring in the initial, medial, or final positions of sequences in the word. This idea is also valid because of the fact that the mastery of segments in codas implies the mastery of 
segments in the onsets, but not vise versa. Based on the SSP, certain ordering of the acquisition of the complex codas can be predicted: clusters with smaller sonority distances between the segments (e.g., $/ \mathrm{nz} /$ from 5 to $4, / \mathrm{lm} /$ from 6 to 5 ) will be acquired later than the ones that have greater difference in sonority values between the elements (e.g., /rk/ from 7 to $1, / 1 \mathrm{t} /$ from 6 to 1 ). Hence, the pronunciation manuals, class assignments have to be prepared accordingly taking into considerations these assumptions.

In the beginning, the focus of instruction has to be directed at the sequences with smaller sonority distances. Once subjects acquire these, the teacher can proceed to strings with a greater SD. All these comments are not intended to sound obligatory.

The progress in L2 acquisition can be treated in a couple of different ways: focusing on an increase in native-like forms, and focusing on a movement towards more advanced stages (not necessarily with the increase in native-like forms). For the Spanish speakers studied here, although the effect of L1 transfer was minimal, the developmental processes such as final consonant cluster reduction and final obstruent devoicing were persistent. Subjects devoiced the final voiced obstruent even in clusters with a large sonority distance between the segments (e.g., /rd/ - the SD is 5 [forwad] $\rightarrow$ [forwat]). Hence, the absence or minimal effect of transfer did not guarantee the success in acquisition for such learners. ESL Spanish speakers must be aware of such processes, and second language teachers should assist them in overcoming these universal phenomena. These processes are considered to be less obvious to the L2 learner than transfer 
processes. For example, the process of final obstruent devoicing is less obvious for a speaker than epenthesis. Lastly, the research regarding L2 phonologies can provide useful data to enhance learning and instruction. 


\section{LIST OF REFERENCES}

Anderson, J.M. (1986). Suprasegmental dependencies. In J. Durand, (Ed.), Dependency and non-linear phonology. London: Croom Helm.

Baptista, B., \& da Silva Filho, J. (1997). The influence of markedness and syllable contact on the production of English final consonants by EFL learners. In J. Leather \& A. James (Eds.), New Sounds 97: Proceedings of the Third International Symposium on the Acquisition of Second-Language Speech (pp. 26-34). Klagenfurt, Austria: University of Klagenfurt.

Beland, R., Caplan, D. \& J.-L. Nespoulous (1990). The role of abstract phonological representation in word production: evidence from phonemic paraphasias. Journal of Neurolinguistics, 5, 125-164.

Benson, B. (1988). Universal preference for the open syllable as an independent process in interlanguage phonology. Language Learning, 38, 221-242.

Bianco, V. (1996). The role of sonority in the prosody of Cowichan. Master's Thesis. University of Victoria.

Broselow, E. (1983). Non-obvious transfer: On predicting epenthesis errors. In S. M. Gass \& L. Selinker (Eds.), Language transfer in language learning (pp. 269-280). Rowley, MA: Newbury House.

Broselow, E., \& Finer, D. (1991). Parameter setting in second language phonology and syntax. Second Language Research, 7, 35-59.

Butt, M. (1992). Sonority and the Explanation of Syllable Structure. Linguistische Berichte, 137, 45-67.

Carlisle, R.S. (1994). Markedness and environment as internal constraints on the variability of interlanguage phonology. In M. Yavas (Ed.), First and second language phonology (pp. 223-249). San Diego, CA: Singular.

Chin, S. (1996). The role of the sonority hierarchy in delayed phonological systems. In T.W. Powell (Ed.), Pathologies of speech and language: Contributions of Clinical phonetics and linguistics (pp. 109-117). New Orleans, LA: A Publication of the International Clinical Phonetics and Linguistics Association.

Clements, G. N. (1990). The role of sonority cycle in core syllabification. In Kingston, J. \& Beckman M. (Eds.), Papers in Laboratory Phonology. Cambridge University Press. 
De Lacy, P. (1997). Prosodic categorization. Master's Thesis. University of Auckland.

De Lacy, P. (2002). The formal expression of scales. Doctoral dissertation. University of Massachusetts Amberst.

Dravina, V. (1990). The Acquisition Process of Consonantal Clusters in the Child: Some Universal Rules? Nordic Journal of Linguistics, 13, 153-163.

Eckman, F. R. (1977). Markedness and the contrastive analysis hypothesis. Language Learning, 27, 315-330.

Eckman, F. R. (1981). On predicting phonological difficulty in second language acquisition. Studies in Second Language Acquisition, 4, 18-30.

Eckman, F. R. (1991). The Structural Conformity Hypothesis and the acquisition of consonant clusters in the interlanguage of ESL learners. Studies in Second Language Acquisition, 13, 23-41.

Eckman, F. R., \& Iverson, G. K. (1993). Sonority and markedness among onset clusters in the interlanguage of ESL learners. Second Language Research, 9, 234-252.

Eckman, F. R., \& Iverson, G. R. (1994). Pronunciation difficulties in ESL: Coda consonants in English interlanguage. In M. Yavas (Ed.), First and second language phonology (pp. 251-265). San Diego, CA: Singular.

Flege, J. E. (1987). Effects of equivalence classification on the production of foreign language speech sounds. In A. James \& J. Leather (Eds.), Sound patterns in second language acquisition (pp. 9-39). Dordrecht, The Netherlands: Foris.

Gierut, J. A. (1999). Syllable Onsets: Clusters and Adjuncts in Acquisition. Journal of Speech, Language, and Hearing research, 42, 708-726.

Greenberg, J. (1978). Some generalizations concerning initial and final consonant clusters. In J. Greenberg, C. Ferguson, \& E. Moravcsik (Eds.), Universals of human language (Vol. 2, pp. 243-279). Stanford, CA: Stanford University Press.

Hammond, R. M. (1999). The Sounds of Spanish. Analysis and Application. Purdue University Press.

Hankamer, J. \& Aissen, J. (1974). The Sonority Hierarchy. Papers from the Parasession on Natural Phonology, 3, 131-145.

Hansen, J. (2001). Linguistic constraints on the acquisition of English syllable codas by native speakers of Mandarin Chinese. Applied Linguistics, 22, 338-365. 
Hogg, R., \& McCully, C. (1987). Metrical phonology: A coursebook. New York: Cambridge University Press.

Jespersen, O. (1904). Lehrbuch der Phonetik. Leipzig and Berlin.

Kenstowicz, M. (1996). “Quality-sensitive stress.” Rivista di Linguistica, 9, 157-187.

Ladefoged, P. (1993). A course in phonetics (3d ed.). New York: Harcourt Brace Jovanovich.

Lado, R. (1957). Linguistics across cultures. Ann Arbor, MI: University of Michigan Press.

LLeo, C. \& Prinz, M. (1996). Consonant clusters in child phonology and the directionality of syllable structure assignment. Child Language, 23, 31-56.

Locke, J. L. (1983). Phonological acquisition and change. New York: Academic Press.

MacKay, D. G. (1972). The structure of words and syllables: evidence from errors in speech, Cognitive Psychology, 3, 210-227.

Major, R. C. (1987). The natural phonology of second language acquisition. In A. James \& J. Leather (Eds.), Sound patterns in second language acquisition (pp. 101-125). New York: Newbury House/Harper \& Row.

Major, R. C. (2001). Foreign accent. The Ontogeny and Phylogeny of Second Language Phonology. New Jersey: Lawrence Erlbaum Associates.

Murray, R. W. \& Vennemann, T. (1983). Sound change and syllable structure in Germanic phonology. Language, 59, 514-528.

Ohala, D. (1999). The influence of sonority on children's cluster reductions. Journal of Communication Disorders, 32, 397-442.

Oller, J. W., \& ZIahosseiny, S. M. (1970). The contrastive analysis hypothesis and spelling errors. Language Learning, 20, 183-189.

Oyama, S. (1976). The sensitive period for the acquisition of a nonnative phonological system. Journal of Psycho-linguistic Research, 5, 261-285.

Paolillo, J. (1995). Markedness in the acquisition of English /1/ and /r/. In F. Eckman, D. Highland, P. Lee, J. Milleham, \& R. Weber (Eds.), Second Language acquisition theory and pedagogy (pp. 275-291). Mahwah, NJ: Lawrence Erlbaum. 
Parker, S. G. (2002). Quantifying the Sonority Hierarchy. Amherst, MA: University of Massachusetts.

Pike, K. L. (1947). Phonemics: A technique for reducing language to writing. Ann Arbor: University of Michigan Publications in Linguistics 3.

Roca, I. \& Johnson, W. (1999). A Course in Phonology. University of Essex.

Romani, C. \& Calabrese, A. (1998). Syllabic constraints in the phonological errors of aphasic Patient. Brain and Language, 64, 83-121.

Selkirk, E. (1982). The Syllable. In H. van der Hulst \& N. Smith (Eds.), The structure of phonological representation. Dordrecht: Foris.

Selkirk, E. (1984). On the major class features and syllable theory. In M. Aranoff \& R. Oehrle (Eds.), Language sound structure: Studies in phonology presented to Morris Halle by his teacher and students. Cambridge, MA: MIT Press.

Selinker, L. (1972). Interlanguage. International Review of Applied Linguistics, 10, 209-231.

Sievers, E. (1901). Grundzuge der phonetic zur einfuhrung in das stadium der lautlehre der indogermanischen sparchen. Leipzig: Bleitkopf and Hartel.

Tarone, E. (1979). Interlanguage as chameleon. Language Learning, 29, 181-191.

Thompson, I. (1991). Foreign accent revisited: The English pronunciation of Russian immigrants. Language Learning, 41, 177-204.

Treiman, R. (1988). The internal structure of syllable. In G. Carlson \& M. Tanenhaus (Eds.), Linguistic structure in language processing. Dordrecht, The Netherlands: Kluwer.

Tropf, H. S. (1987). Sonority as a Variability Factor in Second language Phonology. Sound Patterns in Second Language Acquisition.

Trubetzkoy, N. (1958). Grundzuge der Phonologie [Fundamentals of Phonology].

Wardhaugh, R. (1970). The contrastive analysis hypothesis. TESOL Quaterly, 4, 123-130.

Yavas, M. (1994). Final stop devoicing in interlanguage. In M.Yavas (Ed.), First and second language phonology (pp. 267-282). San Diego, CA: Singular. 
Yavas, M. (1997). The effects of vowel height and place of articulation in interlanguage final stop devoicing. International Review of Applied Linguistics, 35, 15-125.

Yavas, M. \& Gogate, L. (1999). Phoneme awareness in children: a function of sonority. Journal of Psycholinguistic Research, 28, 245-260.

Yavas, M. \& Core, C. (2001). Phonemic awareness of coda consonants and sonority in bilingual children. Clinical Linguistics and Phonetics, 15, 1.

Zec, D. (1995). Sonority constraints on syllable structure. Phonology, 12, 85-129. 


\section{APPENDIX}

This appendix includes list of all words used for the experiment in this thesis.

1. aceptar

2. cocido

3. rechazar

4. envolvió

5. chantajeado

6. agarrado

7. robado

8. atascado

9. bocas

10. el rie

11. quinto

12. estornuda

13. hojas

14. el da

15. guantes

16. el ama

17. plumas

18. monedas

19. alfileres [əksspt]

[kukt]

[rəd3ekt]

[ræpt]

[braIbd]

[græbd]

[robd]

[klogd]

[mauðs]

[læfs]

[fIf $\theta]$

[snIfs]

[livz]

[gIVz]

[gl^vz]

[l^vz]

[penz]

[konz]

[pInz] accept

cooked

reject

wrapped

bribed

grabbed

robbed

clogged

mouths

he laughs

fifth

sniffs

leaves

he gives

gloves

he loves

pens

coins

pins 
20. sueños

[drimz]

dreams

21. novios

[grumz]

grooms

22. florecer

[blumz]

blooms

23. pelicula

[fIlm]

film

24. tranquillo

[kalm]

calm

25. rizo

[k3rl]

curl

26. perla

[p3rl]

pearl

27. mes

$[\mathrm{m} \wedge \mathrm{n} \theta]$

month

28. balanza

[bæləns]

balance

29. adelanto

[ədvæns]

advance

30. cerca

[fens]

fence

31. causadó

[kozd]

caused

32. respire

[briðd]

breathed

33. amadó

[lıvd]

loved

34. movido

[muvd]

moved

35. válvula

[vælv]

valve

36. resolver

[solv]

solve

37. doce

[twelv]

twelve

38. facturas

[bIlz]

bills

39. toros

[bulz]

bulls

40. llamadas

[kolz]

calls 


\begin{tabular}{|c|c|c|c|}
\hline 41. & instrumentos & [tulz] & tools \\
\hline 42. & bolas & [bolz] & balls \\
\hline 43. & aprender & {$[13 \mathrm{~m}]$} & learn \\
\hline 44. & esperma & [sp3rm] & sperm \\
\hline 45. & granero & [born] & barn \\
\hline 46. & máíz & [korn] & corn \\
\hline 47. & exámen & {$[\mathrm{t} \varepsilon s \mathrm{t}]$} & exam \\
\hline 48. & preguntar & [æsk] & ask \\
\hline 49. & izquierda & {$[1 \varepsilon f t]$} & left \\
\hline 50. & regalo & [gIft] & gift \\
\hline 51. & perdió & [mIst] & missed \\
\hline 52. & empujé & {$\left[p u \int t\right]$} & pushed \\
\hline 53. & besó & [kIst [ & kissed \\
\hline 54. & cambió & {$\left[\mathrm{kæ} \int \mathrm{t}\right]$} & cashed \\
\hline 55. & mano & [hænd] & hand \\
\hline 56. & rubio & [blond] & blonde \\
\hline 57. & novio & [boIfrend] & boyfriend \\
\hline 58. & detrás & [bəhaInd] & behind \\
\hline 59. & pulso & {$[\mathrm{p} \wedge l \mathrm{~s}]$} & pulse \\
\hline 60. & duendo & {$[\varepsilon l f]$} & elf \\
\hline 61. & salud & {$[\mathrm{h} \varepsilon \mid \theta]$} & health \\
\hline
\end{tabular}


62. falso

63. miembras

64. espejos

65. metros

66. dueños

67. lámpara

68. tía

69. pensar

70. rosado

71. bombilla

72. frío

73. oro

74. construer

75. enfermera

76. maldicíon

77. cartera

78. caballo

79. adulto

80. cinturón

81. seda

82. assalto [fols]

[membə.z]

[mIrəzz]

[mitaz]

[onaz]

[læmp]

[ænt]

[ $\theta$ Ink]

[pIDk]

[b^lb]

[kold]

[gold]

[bIld]

[n3rs]

[k3rs]

[p3rs]

[hors]

[əd^It]

[belt]

[sIlk]

[esolt] false

members

mirrors

meters

owners

lamp

ant

think

pink

bulb

cold

gold

build

nurse

curse

purse

horse

adult

belt

silk

assault 
83. pajaro

[b3rd]

[k^wad]

[forwad]

[kard]

[dark]

[d3rt]

[hart]

[kort]

90. corte bird

coward

forward

card

dark

dirt

heart

court 